NBER WORKING PAPER SERIES

\title{
TESTING FOR RACIAL DIFFERENCES IN THE MENTAL ABILITY OF YOUNG CHILDREN
}

\author{
Roland G. Fryer \\ Steven D. Levitt \\ Working Paper 12066 \\ http://www.nber.org/papers/w12066
NATIONAL BUREAU OF ECONOMIC RESEARCH
1050 Massachusetts Avenue
Cambridge, MA 02138
February 2006

We would like to thank Lawrence Katz, Kevin Murphy, Andrei Shleifer, and Lawrence H. Summers for helpful discussions on this topic. Katherine Barghaus, Sheldon Bond, Walter Lamberson and Ethan Lieber provided truly outstanding research assistance. Financial support for this study was provided by the National Science Foundation, the Milton Fund at Harvard University, the Sherman Shapiro Research Fund, and the Alphonse Fletcher Sr. Fellowship. Mailing addresses: Roland Fryer, Littauer Building, Harvard University, Cambridge, MA 02138; Steven Levitt, Department of Economics, University of Chicago, 1126 E. 59th Street, Chicago, IL 60637. e-mail: rfryer@fas.harvard.edu; slevitt@uchicago.edu. The views expressed herein are those of the author(s) and do not necessarily reflect the views of the National Bureau of Economic Research.

(C2006 by Roland G. Fryer and Steven D. Levitt. All rights reserved. Short sections of text, not to exceed two paragraphs, may be quoted without explicit permission provided that full credit, including ( $)$ notice, is given to the source. 
Testing for Racial Differences in the Mental Ability of Young Children

Roland G. Fryer and Steven D. Levitt

NBER Working Paper No. 12066

February 2006

JEL No. J15, I20

\begin{abstract}
On tests of intelligence, Blacks systematically score worse than Whites, whereas Asians frequently outperform Whites. Some have argued that genetic differences across races account for the gap. Using a newly available nationally representative data set that includes a test of mental function for children aged eight to twelve months, we find only minor racial differences in test outcomes (0.06 standard deviation units in the raw data) between Blacks and Whites that disappear with the inclusion of a limited set of controls. The only statistically significant racial difference is that Asian children score slightly worse than those of other races. To the extent that there are any geneticallydriven racial differences in intelligence, these gaps must either emerge after the age of one, or operate along dimensions not captured by this early test of mental cognition.

Roland G. Fryer, Jr.

Department of Economics

Harvard University

Littauer Center, M-7

Cambridge, MA 02138

and NBER

rfryer@fas.harvard.edu

Steven D. Levitt

Department of Economics

University of Chicago

1126 East 59th Street

Chicago, IL 60637

and NBER

slevitt@uchicago.edu
\end{abstract}


Blacks in the United States have consistently scored worse than Whites on tests of IQ and academic achievement (Shuey, 1958; Jensen, 1973, 1998; McGurk et al., 1982; Hernstein and Murray, 1994). Among teenagers and adults, the Black-White test score gap is typically one standard deviation in magnitude. Large racial gaps in test scores have been found in children as young as two years old (Scott and Sinclair, 1997), and the one standard deviation racial gap observed later in life is present by age three (Rushton and Jensen, 2005). Even after accounting for a host of demographic and socio-economic factors such as parental income, education, occupation, home environment, birth weight, region, and urbanicity, a substantial Black-White test score gap generally remains. ${ }^{1}$

Asians, on the other hand, tend to have systematically higher mean test scores than those of other races (Campbell et al., 1966; Burkett et al., 1995; Rushton, 1995; Fryer and Levitt, 2004; Brooks-Gunn and Markman 2005).

Some scholars have argued that the combination of high heritability of intelligence (typically above .7, see, for instance, Neisser, 1996) and persistent racial gaps in test scores is evidence of genetic differences across races (Jensen, 1973, 1998; Rushton and Jensen, 2005). As Nisbett (1998) and Phillips et al. (1998) argue, however, the fact that Blacks, Whites, and Asians grow up in systematically different environments makes it difficult to draw strong causal genetically based conclusions.

\footnotetext{
${ }^{1}$ See, for instance, (Campbell et al., 1966; Baughman and Dahlstrom, 1968 Scarr, 1981; Kaufman and Kaufman, 1983; Naglieri, 1986; Bracken, Insko and Sabers, 1987; Humphreys, 1988; Krohn and Lamp, 1989; Brooks-Gunn, 1993a; Brooks-Gunn, Duncan and Kelbanov, 1994, 1996; Phillips et al., 1998; Phillips, 2000; Coley, 2002). A notable exception to this pattern emerges in the Early Childhood Longitudinal Study Kindergarten (ECLS-K) sample of children who entered kindergarten in 1998. This nationally representative sample differs from prior data in that the raw Black-White test score gap at the time children enter kindergarten is substantially smaller than in most prior studies (0.64 standard deviations in math, and 0.41 standard deviations in reading), and that the inclusion of a small number of demographic and socio-economic controls erases the gap (Fryer and Levitt, 2004). Although through the first four years of school, the Black-White test score gap grows substantially, and by the end of third grade these controls no longer account for the differences in test scores across races (Fryer and Levitt, forthcoming).
} 
Data on mental function in the first year of life represents a potentially important piece of evidence to inform this debate. ${ }^{2}$ To the extent that environmental factors play a smaller role at early ages (or alternatively, researchers are better able to measure and control for the environmental factors affecting infants), the presence of an early racial gap in test scores would bolster the argument in favor of a genetic basis for racial differences. On the other hand, an absence of racial differences in mental abilities among children age 9-12 months substantially complicates (but does not rule out) a genetic basis for a racial IQ gap. To the extent that some aspects of adult intelligence only emerge at later stages of development, or that these aspects go unmeasured in the early test of mental function, the genetics story cannot be definitively rejected with these data.

Because of data limitations, prior research has not been able to directly address this question (Rushton and Jensen, 2005). Studies measuring cognitive abilities of young children have been small-scale, rare, and based on convenience samples that are not drawn with the goal of being nationally representative. For instance, many of the samples involve a limited number of babies born in a particular hospital or metropolitan area (Gravem, Ireton and Thwing, 1970; Wilson 1983), preterm infants (Rose and Wallace, 1985), those with birth weights less than 1,500 grams (Dezoete, MacArthur and Tuck, 2003), or children with rare medical conditions (McGarth et al., 2004). The Early Childhood Longitudinal Study Birth Cohort (ECLS-B) is the first large, nationally representative sample with measures of mental functioning (a shortened version of the Bayley Scale of Infant Development (BSID)) for children aged one and under.

\footnotetext{
${ }^{2}$ The usefulness of early tests of mental function depends critically on the assumption that these tests are strongly related to future test scores. Measures of cognitive ability at one year of age (similar to those used in this study) have been found to be strong predictors of test scores later in life by some researchers (Bradley, Caldwell and Elardo, 1975; Wilson, 1983; DiLalla et al., 1990; McGarth, 2004), although other studies report a weaker relationship (Honzik, 1983; Rose and Wallace, 1985; Kopp and McCall, 1990; Anderson, Sommerfelt and Sonnander, 1998). This evidence is discussed in greater detail later in the paper.
} 
Analyzing these data, we find extremely small racial differences in mental functioning of children aged eight to twelve months. With controls only for the child's age and gender, the mean White infant outscores the mean Black infant by .064 standard deviation units - only a tiny fraction of the one standard deviation racial gap observed at older ages. The raw scores for Blacks are indistinguishable from Hispanics and Asians, who also slightly under perform Whites. Adding controls for socio-economic status, home environment, and prenatal circumstances further compresses the observed racial differences. With these covariates, we cannot reject equality in test scores across any of the racial/ethnic groups examined, except Asians. In our sample Asian babies do slightly, but statistically significantly, worse than babies of other races.

When we calibrate these results to a simple model in which test scores are affected by both genes and environment, the characterization that best matches the observed data is one in which there are small mean racial differences in intelligence, environmental factors become increasingly important determinants of test scores as children age, and there are large mean racial differences (roughly 1.5 standard deviations) in environment.

These findings pose a substantial challenge to the simplest, most direct, and most often articulated genetic stories regarding racial differences in mental function. They do not, however, preclude systematic genetic differences across races as an explanation for later observed test score gaps if, for instance, racial gaps are concentrated in higher-order thinking which only emerges later in life. The late emergence of racial differences in test scores is also consistent with the existence of a gene-environment interaction such as argued by Dickens and Flynn (2001). In their model, a positive feedback loop exists 
between genes and environment, which over time serves to magnify small initial differences when genetics and environmental circumstances are positively correlated.

The remainder of the paper is structured as follows. Section II describes the data. Section III presents the basic empirical estimates. Section IV assesses the sensitivity of the findings to alternative specifications. Section V develops a simple model of genes and environment and explores the extent to which particular characterizations of the model are able to reproduce the observed patterns in the data. Section VI concludes.

\section{The Data}

The data we analyze, the Early Childhood Longitudinal Survey Birth Cohort (ECLS-B), is a nationally representative sample of over 10,000 children born in 2001. The first wave of data collection was performed when most of the children were between eight and twelve months of age. ${ }^{3}$ The data set includes an extensive array of information from parent surveys, interviewer observation of parent-child interactions, and mental and motor proficiency tests. Further details on the study design and data collection methods are available at the ECLS website (http://nces.ed.gov/ecls).

To measure mental proficiency, the ECLS-B uses an abbreviated version of the BSID known as the Bayley Short Form-Research Edition (BSF-R), which was designed to measure the development of children eight to eleven months of age in five broad areas: exploring objects (e.g., reaching for and holding objects), exploring objects with a purpose (e.g., trying to determine what makes the ringing sound in a bell), babbling, early problem solving (e.g., when a toy is out of reach, using another object as a tool to retrieve the toy), and communicating with words. A child's score is reported as a proficiency

\footnotetext{
${ }^{3}$ These children will eventually be resurveyed four times between the present and first grade. At the present time, only the first wave of data is available.
} 
level, ranging from 0 to 1 on each of the five sections. These five proficiency scores have also been combined into an overall measure of cognitive ability using standard scale units. Most of our analysis focuses on this overall metric. The test is administered by a trained interviewer and takes twenty-five to thirty-five minutes to complete.

Because this particular test instrument is newly designed for ECLS-B, there is no direct evidence regarding the correlation between performance on this exact test and outcomes later in life. There is, however, a substantial literature of longitudinal studies relating BSID test scores of children aged eight to twelve months to tests of intelligence later in life. Figure 1 provides a graphical representation of the correlations observed in this prior literature, weighting the estimates of the various papers by the number of subjects included in each study. ${ }^{4}$ The horizontal axis is the age in years that the subsequent tests were administered and the vertical axis contains the average correlation between the BSID score and another measure of intelligence. The figure shows that the average correlation between BSID and future IQ scores starts very high and decreases as children age, stabilizing with an average correlation around 0.3 at approximately five years of age. For purposes of comparison, when older children are given achievement scores three years apart, the correlation between scores is on the order of 0.6 (Cruse et al., 1996). ${ }^{5}$

A correlation of .3 between the BSID and future measures of IQ means that the BSID score explains only nine percent of the variation in future test scores for a particular individual. Even though one can explain relatively little of the within-person variation over time in test scores, one would still expect to observe large differences in

\footnotetext{
${ }^{4}$ Appendix Table 1 list the full set of papers and reported correlations on which Figure 1 is based.

${ }^{5}$ Other infant tests, such as the Cattell Infant Intelligence Scale, Gesell Development Schedules, or BrunetLezine Development Scales, have a substantially lower correlation with later achievement than does the BSID (Escalona and Moriarty, 1961; Karlberg et al., 1968; Birns and Golden, 1972).
} 
mean test scores by race on the BSID given the prior evidence. Yeates, et al. (1983), for instance, report a correlation between maternal IQ (assessed using the Wechsler Adult Intelligence Scale at the time of interview) and the BSID of twelve month old children as .36. For purposes of comparison, the correlation between maternal IQ (using the same metric) and the well-known Stanford-Binet at three years old is .39. Given the observed one standard deviation in maternal IQ between Whites and Blacks, a correlation of .36 between child's BSID and mother's IQ would imply expected mean differences between White and Black one-year olds of .36 standard deviations. ${ }^{6}$

The ECLS-B sample includes observations on 10,688 children. For 556 of these individuals, no mental ability test was performed. These subjects are dropped from the analysis. This is the only exclusion we make from the sample. ${ }^{7}$ Throughout the analysis, the results we report are weighted to be nationally representative using sampling weights included in the data set. ${ }^{8}$

Table 1 provides summary statistics by major racial/ethnic group in ECLS-B.

The mutually exclusive and collectively exhaustive racial/ethnic categories we report are: non-Hispanic Whites (which we simply deem "White”), non-Hispanic Blacks ("Black”), Hispanics, Asians/Pacific Islander (“Asian”), and other race (which combines children characterized as Native American, mixed race, or other race). The top panel of the table reports means and standard deviations by race on the overall measure of mental ability. For ease of interpretation of the regressions, the overall test score has been normalized to

\footnotetext{
${ }^{6}$ Indeed, given the results cited in Rushton and Jensen (2005) regarding one standard deviation racial gaps in IQ tests administered at age 3 and the stability in Black-White differences over time, one might expect to observe racial differences in the BSID of one standard deviation.

${ }^{7}$ In cases where there are missing values for another of the covariates, we set these missing observations equal to zero and add an indicator variable to the specification equal to one if the observation is missing and equal to zero otherwise.

${ }^{8}$ A comparison of the ECLS-B sample characteristics with known national samples such as the US Census and the Center for Disease Control's Vital Statistics confirms that the sample characteristics closely match the national averages.
} 
have a mean of zero and a standard deviation of one for the sample as a whole. Whites score .018 standard deviations better than the sample mean on the overall mental measure.

The next panel of the table presents basic demographic characteristics, which are generally similar across groups. Age at testing is approximately equal across races. As would be expected, Blacks are over represented in the South and underrepresented in the West. Asians and Hispanics are seen in greatest numbers in the West. The fraction of girls and boys are similar across all racial groups.

The third panel has variables capturing the home environment, including socioeconomic status (SES) quintiles, number of siblings, family structure, mother's age, and an interviewer rating of the effectiveness of the "parent as a teacher" based on observation of parent-child interactions in a structured problem-solving environment. ${ }^{9}$ The socio-economic status measure is constructed by ECLS and includes parental income, occupation, and education. Whites and Asians are concentrated in the higher ranges of the SES distribution; Blacks, Hispanics, and the "other race" category have below average SES. Roughly 90 percent of White and Asian infants are living in households with two biological parents compared to only 41 percent among Blacks. On average, children in our sample have approximately one sibling; Asian children have slightly fewer and Black kids slightly more. White and Asian mothers tend to be older. White parents fare better than the other racial groups on the interviewer evaluation of "parent as teacher" effectiveness.

\footnotetext{
${ }^{9}$ The "parent as a teacher evaluation" is based on the Nursing Child Assessment Teaching Scale (NCATS). The NCATS scale is composed of 73 binary (yes/no) items that are scored by trained observers. The NCATS coding system has two main scales: the parent scale, which has 50 items, and the child scale with 23 items. The parent scale of the NCATS focuses on the caregiver's use of a "teaching loop," which consists of four components: (1) getting the child's attention, and setting up the expectations for what is about to be done; (2) instruction giving; (3) letting the child respond to teaching; and (4) feedback, on the child's attempts to do the task (Nord, 2004). The total parent score can range from 0 to 50 (Yes=1, No=0).
} 
The final panel of Table 1 presents statistics on the prenatal circumstances of the children. Extremely low birth weight $(<1,500$ grams $)$ and premature birth are most common among Blacks and least frequent for Whites and Asians. Twins and higher order births are much more frequent among Whites, due primarily to the greater use of infertility techniques such as in vitro fertilization (Hamilton and McManus, 2004).

Figure 2 plots the density of BSID test scores by race. The test score distributions for infants of different races are essentially indistinguishable visually. Note that this is in stark contrast to the distribution of other measures of intelligence for older children in prior studies. Figure 2 makes the main point of the analysis. In the regression analysis that follows, we control for a wide range of other factors, but the basic conclusion suggested by Figure 2 is unchanged.

III. Racial Differences in the Mental Ability of Young Children

Our empirical approach involves weighted least squares estimation of equations taking the general form:

$$
\operatorname{MENTALTEST}_{i}=\sum_{R} \beta_{r} R_{i}+\Gamma X_{i}+\varepsilon_{i}
$$

where $i$ indexes individuals and $r$ corresponds to the racial group to which an individual belongs. MENTAL TEST reflects either the overall test score, or one of the underlying components of the test - depending on our particular specification. The vector $X$ captures a wide range of possible control variables, and $\varepsilon$ is an error term. Also included in all specifications are interviewer-fixed effects, which adjust for any mean differences in scoring of the test across interviewers. ${ }^{10}$

\footnotetext{
${ }^{10}$ Each of the 13 regions was staffed by one field supervisor and between 14 and 19 interviewers, for a total of 256 field staff (243 interviewers), who conducted an average of 42 child assessments each. The number
} 
The basic results for the coefficients on the race variables are presented in Table 2. The omitted race category is "Whites," so the other race coefficients are relative to that omitted group. Each column reflects a different regression. The first column includes only interviewer-fixed effects. As in the raw data, Blacks, Hispanics, Asians, and "Other" races slightly under perform Whites. Only for Blacks can one reject the null of no difference at the .05 level.

As one moves from left to right in Table 2, the set of covariates is progressively expanded. The coefficients on the other covariates are not shown in the table, but full estimation results can be found in Appendix Table 2. Column (2) adds controls for age at which the test is administered and the gender of the child. Because the age the test is taken is such an important determinant of test performance, we adopt an extremely flexible, non-parametric functional form for age (including age in days linearly, age in days squared, all the way up to a quintic in age). The R-squared in the regression jumps substantially with the inclusion of the age and gender controls (from .14 in the first column to .68 in the second column); which is mainly due to the age controls. A child taking the test at age eleven months is predicted to perform .66 standard deviations better than the same child when tested at age nine months, according to our estimates. Girls outscore boys by .06 standard deviations on average, a difference that persists throughout all our specifications. Including these controls improves the performance of Whites versus other races because Whites are slightly younger on average when tested.

Column (3) adds indicators for the family's SES quintile. The SES variable (not shown in the main table) enters with the expected sign, i.e. higher SES children score higher on the test, but the magnitude of the effects are small (a top quintile SES child races (James et al., 2004). 
outscores a bottom quintile child by .08 standard deviations). Inclusion of the SES variable shrinks the coefficient on Black and "other race."

Adding a range of other controls for a child's home environment (family structure, mother's age, number of siblings, and region dummies) shrinks the gap between Whites and each of the other races. The only race coefficient that remains statistically significant is the underperformance by Asians of roughly .06 standard deviations. Adding a control for the interviewer assessment of "parent as teacher" in column (5) further shrinks all of the race coefficients.

The final column adds controls for a range of prenatal condition variables (birth weight, premature birth, and multiple births). The coefficient on Black becomes very close to zero; the other race variables are not greatly affected. All the point estimates are substantively small: the largest gap, between Asians and Whites, is only .048 standard deviation units. After Whites, the group performing best is Blacks, although one cannot reject equality between Blacks and any of the other groups.

IV. Sensitivity Analysis and Extensions of the Basic Analysis

Although on average we observe only minor differences across races in mental test performance, important differences in sub-groups of the population remain a possibility. Table 3 presents a wide range of estimates to test the sensitivity of our basic results. Each row of the table presents the race coefficients from a separate regression. In each case, the specification uses the full set of controls included in the final column of the preceding table.

The top row of the table simply reproduces the baseline estimates from column (6) of Table 2. The next row presents unweighted estimates. The subsequent rows 
segment the table by gender, SES quintile, family structure, region, urbanicity, and birth weight. Of the 104 coefficients presented, twelve are statistically significant at the .05 level; almost all of these correspond to underperformance by Asians.

Evidence exists that there are racial differences in early motor skills, with Blacks outperforming other races and Asians lagging (Malina, 1988; Colombo, 1993; Toy et al. 2000). In our data, both Blacks and Asians outperform Whites on the test of motor skills. If the early life test of mental abilities depends on both sensorimotor and intellectual skills, precocity in the former might mask a deficiency in the latter among Blacks. Therefore, we report results controlling for an individual's performance on the test of motor skills. The black coefficient increases from -.002 to -.034 with the inclusion of motor skills, though the absolute magnitude of the difference continues to be extremely small. All other racial groups remain essentially unchanged.

The final sensitivity test we report corresponds to the age at which the test of mental function is administered. In prior studies, the correlation between BSID tests and later IQ scores were higher when the BSID was administered to older infants (Bayley, 1955). Thus, if true, racial differences in intelligence are being masked by limitations of the BSID to ascertain these differences for children at young ages, then we would expect the racial differences in our sample to be smaller among the youngest children sampled and larger among the older children sampled. The final rows of Table 3 provides no evidence of this for Blacks, although for the "other race" category, the gaps are steadily rising versus Whites with age.

\section{A. Investigating the individual components underlying the composite mental test score}


The overall test score is made up of five underlying components: exploration, exploration with purpose, babbling, problem solving, and word use. Table 4 presents regression estimates on each of these parts of the test. Each column corresponds to a different component of the test. The mean level of proficiency and standard deviation in that mean are reported at the bottom of each column. Note that we have not transformed the proficiency scores on the sub-tests to have mean zero and standard deviation one, so the estimates in this table are not directly comparable to those of the two preceding tables. Because there is so little variation on some of the sub-tests, transforming each of the tests to have the same standard deviation across children will artificially inflate test score differences on the sections with little variation (i.e., explores objects and uses words). Only the race coefficients are shown in the tables. The specifications include the full set of controls, mirroring column (6) of Table 2. Nineteen of the twenty race coefficients are negative, implying that in virtually all of the cases the omitted group (Whites) shows greater proficiency. The magnitudes of the estimates, however, are quite small: less than one-half a percentage point difference in proficiency in almost all cases. In only one instance (less babbling done by Asians infants) is the gap between another group and Whites statistically significant at the .05 level. The only positive estimate in the table is associated with greater (but not statistically significantly different) babbling by Blacks. Thus, there is little in the underlying test components to alter the conclusions suggested by the composite measure of mental function.

V. Interpreting the results through the lens of a simple model of genes and environment A number of stylized facts emerge from the analysis and literature reviewed in the previous sections. In this section, we build a highly stylized model of the factors 
underlying test scores. We then calibrate the model using research-generated parameter estimates to determine how successful competing theories are in reconciling the facts described above.

\section{A. The model}

We model test scores as determined by four factors: intelligence (denoted $I$ ), environment $(E)$, and an error term composed of two parts, a person-age specific error component $(\theta)$ which is constant for an individual taking repeated versions of the test at a given age, and a random noise term $(\mathcal{\varepsilon})$ which varies with each administration of the test. Both error terms are assumed to be mean zero. The person-age specific error term captures the fact that different skills are tested at different ages (e.g., at early ages, babbling is one of the measures, at later ages, how quickly one can complete a maze). An individual may excel at the particular skills emphasized when testing is done at one age, in which case the internal validity of the test will be high, but the predictive value for future test scores (when other skills are emphasized) may be much lower. Formally, we model the test score $S$ as generated by:

$$
S_{i t}^{*}=\alpha_{t} I_{i t}+\beta_{t} E_{i t}+\varepsilon_{i t}+\theta_{i t}
$$

where $i$ indexes individuals and $t$ corresponds to the age at which the test is taken. Our primary focus is on two periods $t$, which we denote $e$ (age 8-12 months) and $l$ for "later" in life (roughly age 5 and beyond).

The test scores, measure of intelligence, and environmental factors are all scaled in arbitrary units. Without loss of generality, we normalize the variables $I$ and $E$ to have mean zero and variance equal to one. For simplicity, we will assume in the formal modeling that there is a zero covariance between $I, E$, and the two error terms. We will 
also assume that $\operatorname{cov}\left(\theta_{i e} \theta_{i l}\right)=0, \operatorname{cov}\left(\varepsilon_{i e} \varepsilon_{i l}\right)=0$, and $\operatorname{cov}\left(\theta_{i t} \varepsilon_{i t}\right)=0$ for all $t$. For simplicity, we assume that environment and intelligence are uncorrelated, only briefly discussing at the end of the section the implications for the model of allowing for feedback effects between intelligence and environment. We do allow for correlations between intelligence at early and late points in life, and likewise environment may be correlated over time for an individual. The coefficients on intelligence and environment are allowed to vary depending on the age at which the test is taken.

Intelligence and environment are not directly observable. Rather, we see only a test score. The test score is also measured in arbitrary units. We transform this test score, which already has mean zero given the assumptions above, to have variance equal to one across the population by dividing through by the standard deviation of the test, calling the resulting variable $S_{i t}$ :

$$
S_{i t}=\frac{\alpha_{t} I_{i t}+\beta_{t} E_{i t}+\theta_{i t}+\varepsilon_{i t}}{\left(\alpha_{t}^{2}+\beta_{t}^{2}+\lambda_{t}^{2}+\sigma_{t}^{2}\right)^{1 / 2}}
$$

where $\lambda_{t}^{2}$ and $\sigma^{2}$ denote the variances of $\theta_{i t}$ and $\varepsilon_{i t}$ respectively.

Given our assumptions above, the internal reliability of the test as measured by the correlation in test scores when the same person takes the test twice at the same age is

(3) $\operatorname{corr}\left(S_{i t}, S_{i t}^{\prime}\right)=\frac{\alpha_{t}^{2}+\beta_{t}^{2}+\lambda_{t}^{2}}{\alpha_{t}^{2}+\beta_{t}^{2}+\lambda_{t}^{2}+\sigma_{t}^{2}}$

The correlation between an individual's test scores early in life and when later tested is given by

$$
\operatorname{corr}\left(S_{i e}, S_{i l}\right)=\frac{\alpha_{e} \alpha_{l} \operatorname{cov}\left(I_{e}, I_{l}\right)+\beta_{e} \beta_{l} \operatorname{cov}\left(E_{e}, E_{l}\right)}{\left(\alpha_{e}^{2}+\beta_{e}^{2}+\lambda_{e}^{2}+\sigma_{e}^{2}\right)^{1 / 2}\left(\alpha_{l}^{2}+\beta_{1}^{2}+\lambda_{1}^{2}+\sigma_{1}^{2}\right)^{1 / 2}}
$$


Because the variance of each of the test scores is normalized to one, the correlation between the test scores is also the covariance between the test scores.

Assuming that the same equations determine Black and White test scores and that the tests are not racially biased (in the sense that $\theta$ and $\varepsilon$ are mean zero for all races), the mean racial test score gap at a point at a given age is represented by

$$
\bar{S}_{W, t}-\bar{S}_{B, t}=\frac{\alpha_{t}\left(\bar{I}_{W, t}-\bar{I}_{B, t}\right)+\beta_{t}\left(\bar{E}_{W, t}-\bar{E}_{B, t}\right)}{\left(\alpha_{t}^{2}+\beta_{t}^{2}+\lambda_{t}^{2}+\sigma_{t}^{2}\right)^{1 / 2}}
$$

where $W$ and $B$ correspond to White and Black, respectively, and a bar over a variable represents the sample mean.

\section{B. Reconciling the empirical estimates of the parameters with the model}

The model presented above, in its most general form, imposes few restrictions on the processes generating the data. For instance, an individual's intelligence and environment are allowed to change over time, as is the contribution of each of those factors in determining the test score. In what follows, we consider the extent to which more restrictive versions of the model that correspond to plausible theories of nature vs. nurture are able to reproduce observed patterns in the data.

Table 5 presents the values that we use as stylized facts in calibrating the model. The first two rows of the table correspond to the internal reliability of the test. Andreassen and Fletcher (2005) report an internal reliability of .80 for the BSID test at an early age. Later intelligence tests have been found to have internal reliability of .94 (White et al., 2004). Another parameter of interest is the correlation between test scores early and later in life, as captured by equation (4). Based on Figure 2, we assign a value of .30 to that correlation. Also relevant to pinning down our model is the correlation 
between test scores when the same individual takes the test later in life, but separated by several years. We assume a correlation of .60 in that case (Cruse et al., 1996). The estimated Black-White test score gap at young ages is taken as .06 based on our findings, compared to a gap of 1.0 at later ages based on prior research (Rushton and Jensen, 2005). The measured correlation between test scores early and late in life and parental test scores is also useful to the analysis. Based on prior research, we take these two correlations as .36 and .39 respectively.

The primary puzzle raised by our results is the following: how does one generate small racial gaps on the BSID test scores administered at ages 8-12 months and large racial gaps in tests of mental ability later in life, despite the fact that these two test scores are reasonably highly correlated with one another $(\rho=.3)$, and both test scores are similarly correlated with parental test scores $(\rho>.35)$ ?

\section{Model 1: Intelligence and environment are constant over time}

The simplest version of the model is one in which an individual's intelligence and environment stay fixed over time, and the relationship between the test score and these two factors is the same both early and later in life. Mathematically, in such a model, $I_{i e}=$ $I_{i l,} E_{i e}=E_{i l,} \alpha_{e}=\alpha_{l}$, and $\beta_{e}=\beta_{l, .}$ To solve the model, it is also convenient to assume that $\lambda_{e}^{2}=\lambda_{l}^{2}$. Given these restrictions and noting the observed correlation in the data, equation (4) above simplifies to

$$
\operatorname{corr}\left(S_{i e}, S_{i l}\right)=\frac{\alpha^{2}+\beta^{2}}{\left(\alpha^{2}+\beta^{2}+\lambda^{2}+\sigma_{e}^{2}\right)^{1 / 2}\left(\alpha^{2}+\beta^{2}+\lambda^{2}+\sigma_{1}^{2}\right)^{1 / 2}}=.30
$$

Rearranging equation (3) and imposing the observed levels of internal reliability for the tests administered early and late in life yields 


$$
\begin{aligned}
& \text { (3') } \alpha^{2}+\beta^{2}+\lambda^{2}+\sigma_{e}^{2}=\frac{\alpha^{2}+\beta^{2}+\lambda^{2}}{.80} \\
& \text { (3') } \alpha^{2}+\beta^{2}+\lambda^{2}+\sigma_{l}^{2}=\frac{\alpha^{2}+\beta^{2}+\lambda^{2}}{.94}
\end{aligned}
$$

Substituting (3') and (3'') into the denominator of equation (4') eliminates $\sigma_{e}^{2}$ and $\sigma_{l}^{2}$ from (4), yielding

$$
\frac{\alpha^{2}+\beta^{2}}{\left(\alpha^{2}+\beta^{2}+\lambda^{2}\right)}=.345 \text {. }
$$

In order for this simplest model to reconcile the high internal reliability of the tests with the much lower correlations for an individual across ages, almost two-thirds of the variance in test scores at a point in time is being driven by the person-age specific error term, rather than by intelligence or environment. Since the impact of intelligence and environment are held fixed, the only thing that varies over time is the person-age specific error term. The necessary variance in the person-age specific error term required to fit the data would appear to be far too large to be realistic. Furthermore, in this simplest of models, the racial test score gap observed early and late in life should be similar, which is not the case. Consequently, the data are inconsistent with a simple characterization in which both the level of an individual's intelligence and environment remain fixed over time and the importance of those factors in determining test scores.

\section{Model 2: Intelligence has not yet emerged early in life}

An alternative model is one in which an individual's intelligence has not yet fully developed at age 1 , but otherwise the restrictions in the simple model are maintained. In the most extreme conceptualization of this view, one would assume that $I_{i e}=0$ for all 
individuals. Such a model can generate a small racial test score gap early in life and a one-standard deviation gap later in life if $\bar{I}_{W, l}>\bar{I}_{B, l}$. This model still implies a large variance on the person-age specific shock. Most importantly, the model cannot explain how one observes a similar degree of correlation between parental test scores and their children's test scores both early and later in life. Given the high degree of heritability in intelligence, one would expect that if early test scores do not reflect intelligence, then they should correlate much less strongly with parental test scores than later tests. ${ }^{11}$

\section{Model 3: Intelligence remains fixed; environment grows in importance over time}

One simple parameterization of the model that can generate results that are more consistent with the observed correlations is one in which (1) intelligence remains fixed for an individual over time, (2) the early and late test scores are equally influenced by intelligence, and (3) the importance of environmental factors grows with age. ${ }^{12} \mathrm{~A}$ mathematical characterization of these assumptions implies $I_{i e}=I_{i l}, \alpha_{e}=\alpha_{l}, \beta_{e}=0$, and $\beta_{l}>0$. As in the earlier model, for convenience we will impose $\lambda_{e}^{2}=\lambda_{l}^{2}$, although this assumption could be relaxed. Under these assumptions equation (4) becomes

$$
(4, ') \operatorname{corr}\left(S_{i e}, S_{i l}\right)=\frac{\alpha^{2}}{\left(\alpha^{2}+\lambda^{2}+\sigma_{e}^{2}\right)^{1 / 2}\left(\alpha^{2}+\beta_{1}^{2}+\lambda^{2}+\sigma_{1}^{2}\right)^{1 / 2}}=.30 .
$$

Solving for $\sigma_{e}^{2}$ and $\sigma_{l}^{2}$ using the internal validity of the tests leads to

\footnotetext{
${ }^{11}$ One possible line of argument in favor of such a model would be that early in life parents exert an enormous influence on the child's environment, and that there is a strong correlation between the parent's early environment and the child's. Arguing against this conjecture is the relatively weak impact of observable dimensions of environmental factors like SES in our test score regressions. Furthermore, since the internal reliability of the early test score is lower, a similar correlation between parental test scores and a child's test scores early and later in life actually implies an even stronger correlation between parental and child early in life, if we are able to measure the child early and late in life.

${ }^{12}$ Alternatively, one can allow for the environmental impact to be similar early and late in life, with Black and White environments being similar on average early in life, but with Blacks experiencing much worse environments later in life.
} 


$$
\operatorname{corr}\left(S_{i e}, S_{i l}\right)=\frac{\alpha^{2}}{1.153^{*}\left(\alpha^{2}+\lambda^{2}\right)^{1 / 2}\left(\alpha^{2}+\beta^{2}+\lambda^{2}\right)^{1 / 2}}=.30 .
$$

The racial test score gaps early and late in life are respectively

$$
\begin{aligned}
& \bar{S}_{W, e}-\bar{S}_{B, e}=\frac{\alpha\left(\bar{I}_{W}-\bar{I}_{B}\right)}{1.118^{*}\left(\alpha^{2}+\lambda^{2}\right)^{1 / 2}}=.06, \text { and } \\
& \bar{S}_{W, l}-\bar{S}_{B, l}=\frac{\alpha\left(\bar{I}_{W, t}-\bar{I}_{B, t}\right)+\beta_{l}\left(\bar{E}_{W}-\bar{E}_{B}\right)}{1.031 *\left(\alpha_{t}^{2}+\beta_{l}^{2}+\lambda^{2}\right)^{1 / 2}}=1.0
\end{aligned}
$$

To close the model, we make the additional assumption that all of the variation in test scores when children take the test later in life but three years apart (such test scores are correlated .60) is due to the error terms, rather than changes in intelligence or environment. This assumption will tend to exaggerate the magnitude of $\lambda^{2}$. That final assumption yields a final equation

(10) $\operatorname{corr}\left(S_{i l}, S_{i l+3}\right)=\frac{\alpha^{2}+\beta_{l}^{2}}{1.064 *\left(\alpha^{2}+\beta_{l}^{2}+\lambda^{2}\right)}=.60$,

where we have already solved out for the $\varepsilon$ term in equation (10) using the internal reliability of the test later in life.

Equations (7)-(10) contain five unknowns ( $\alpha, \beta_{l}, \lambda$, and the mean racial gaps in $I$ and $E$ ). Without loss of generality, we can restrict $\alpha=1$, with $\beta$ and $\lambda$ now scaled relative to $\alpha,{ }^{13}$ leaving four equations and four unknowns. Tedious algebraic manipulation yields a solution to this set of equations such that $\alpha^{*}=1, \beta^{*}=1.145,\left(\lambda^{2}\right)^{*}=1.144,\left(\bar{I}_{w}-\bar{I}_{B}\right)^{*}=.102$, and $\left(\bar{E}_{w}-\bar{E}_{B}\right)^{*}=1.624$.

This model is able to generate the observed racial test score gaps both early and late in life, and it does so with a smaller, more realistic variance on the person-age

\footnotetext{
${ }^{13}$ This can be seen by multiplying both the numerator and denominator of the left-hand sides of equations (7)-(9) by $1 / \alpha$.
} 
specific error term. ${ }^{14}$ This model can also reproduce the high levels of internal reliability of the tests, fit the .30 correlation between early and later test scores, and plausibly generate similar correlations between parent and child test scores early and later in life. ${ }^{15}$ In this model, a one-standard deviation change in environment has roughly the same impact on test scores as does a one-standard deviation change in intelligence. The required mean difference in environment between Blacks and Whites is slightly more than 1.5 standard deviations. This magnitude of environmental difference, while large, does not seem implausible. Using estimates from Fryer and Levitt (2004), there is a .75 standard deviation difference between Blacks and Whites in socioeconomic status, .83 standard deviations in the number of children's books in the home, 1.30 standard deviation difference in female-headed households, 1.51 standard deviation difference in whether or not one feels safe in their neighborhood, a 1.5 standard deviation difference in the percentage of kids in their school who participate in the free lunch program, and a 1.31 difference in the amount of loitering reported around the school by non-students. ${ }^{16}$ Adding to this the possible role of difficult to measure factors such as racial discrimination or behavioral differences discouraging achievement (e.g. Austen-Smith and Fryer, 2005), makes a 1.5 standard deviation difference in environment between Blacks and Whites quite conceivable.

\footnotetext{
${ }^{14}$ Whereas in the earlier model the person-age specific error term had to represent more than two-thirds of the overall variance in test scores, in this model, about one-third of the variance comes from this source.

${ }^{15}$ Early in life, all of the variation in test scores is driven by intelligence, which is highly heritable, generating a parent-child correlation. Later in life, the intelligence channel continues to operate, but there is an additional effect operating through environment. If the cross-generation correlation in environment was as strong as that in intelligence, then one would expect to observe a higher correlation between later test scores and parental test scores than is the case for early tests. In practice, however, the crossgeneration correlation in environment is much weaker than that for intelligence. Consequently, one could plausibly generate similar correlations between a parent's test score and a child's test score early and late in life in this model.

${ }^{16}$ All estimates are derived by taking the difference in the mean of a variable between Blacks and Whites and dividing by the standard deviation for Whites. The socioeconomic composite measure contains parental income, education, and occupation.
} 


\section{More complicated models}

In practice, it is likely that the true model generating the data incorporates elements of both of the last two models discussed: allowing for intelligence to be only partially formed at the time of the early test, and letting the importance of environment grow with age. Such a model would allow us to fit the basic facts of the data, but with smaller estimate on the coefficient on environmental differences. Allowing for geneenvironment interactions as in Dickens and Flynn (2001), which introduces a multiplier effect with age, would further move the model in that direction.

\section{Discussion}

The debate over racial differences in intelligence is among the most divisive in the social sciences. Utilizing a newly available, nationally representative data set with measures of mental function among children before their first birthday, we find little evidence of systematic racial differences. Some substantively small, but statistically significant differences are present in the raw data. Including controls for age, socioeconomic status, home environment and prenatal environment largely erase these small differences. A simple calibration exercise suggests that many of the basic facts in the data can be generated from a model in which there are small mean differences in intelligence across races, but large environmental differences across races that become increasingly important as children age.

Comparing the magnitude of differences observed in these data to prior studies of children, teens, and adults puts into perspective how small the observed differences are in this analysis of infants. Phillips et al. (1998), which investigates test outcomes among 
kindergarteners in the early cohorts of the Children of the National Longitudinal Survey of Youth (NLSY), finds some of the smallest published racial gaps. They report a raw Black-White gap of over one standard deviation, which shrinks to one-third of a standard deviation with the inclusion of myriad controls. Those gaps are an order of magnitude larger than what we find among infants. ${ }^{17}$

Although damaging to the hypothesis that genetic differences are at the root of racial gaps in intelligence, the results of our analysis do not preclude a possible role for a genetic contribution to racial differences in intelligence for a number of reasons. First, one could reasonably argue that the control variables we include in the regression analysis are themselves partly genetically determined. By controlling for factors such as socio-economic status and birth weight (which systematically differ across races), we may indirectly be parsing out important channels through which genetics are operating. The fact that the raw differences in test performance across races are so small, however, makes this argument largely moot.

A second possible argument one can make against our findings is that the particular form of the BSID used in ECLS has not been proven to correlate with future measures of intelligence. The relationship between other forms of the BSID and later test scores calls this argument into question. Nonetheless, the answer to this inquiry cannot be definitively determined in this data set at the present time. In principle, however, retesting the subjects as they age provides a means of resolving this question.

A third argument in defense of the genetic story is that the BSID test is racially biased in favor of Blacks. This is an issue worthy of further testing, although the fact that

${ }^{17}$ As noted earlier, one possible explanation for the growing racial gap with age is a genetics-environment interaction as proposed by Dickens and Flynn (2001). 
small racial differences are observed across the four different skills that comprise the test is circumstantial evidence against this claim.

A final argument in defense of the genetic story would be one in which the racial differences are concentrated in higher order thinking (or general intelligence, "g", see Jensen, 1998) which may not yet have emerged among one year olds. Unlike the argument in the preceding paragraph, it is not clear that such a hypothesis is easily tested even with the passage of time. 


\section{References}

Andreassen, C. and P. Fletcher. Early Childhood Longitudinal Study Birth Cohort. Psychometric Analysis. Volume 1 of the ECLS-B Methodology Report for the 9 Month Data Collection. US Department of Education. 2005. Washington, DC. National Center of Education Statistics.

Acheson, Shawn and Molfese, Victoria J. "Infant and Preschool Mental and Verbal Abilities: How Are Infant Scores Related to Preschool Scores?" International Journal of Behavioral Development, 1997, 20(4), pp. 595-607.

Andersson, Helle W.; Sommerfelt, Kristian and Sonnander, Karin. "Gender and its contribution to the prediction of cognitive abilities at 5 years." Scandinavian Journal of Psychology, 1998, 39, pp. 267-74.

Austan-Smith, David, and Roland Fryer "An Economic Analysis of 'Acting White.' Quarterly Journal of Economics, 2005, 120 (2), pp. 551-583.

Barnard, Kathryn E.; Bee, Helen L.; Clark, Barbara; Eyres, Sandra J.; Gray, Carol A.; Hammond, Mary A.; Snyder, Charlene and Spietz, Anita L. "Prediction of IQ and Language Skill from Perinatal Status, Child Performance, Family Characteristics and Mother-Infant Interaction." Child Development, 1982, 53(5), pp. 1134-56.

Baughman, Earl and Dahlstrom, Grant W. Negro and White Children: A Psychological Study in the Rural South. New York: Academic Press, 1968.

Bayley, Nancy. "On the Growth of Intelligence." American Psychologist, 1955, 10, pp.805-18.

Bethel, James; Green, James L.; Kalton, Graham and Nord, Christine. Early Childhood Longitudinal Study, Birth Cohort (ECLS-B), Sampling. Volume 2 of the ECLS-B Methodology Report for the 9-Month Data Collection, 2001-02. Washington, DC: U.S. Department of Education, NCES, 2004.

Birns, Beverly and Golden, Mark. "Prediction of intellectual performance at 3 years from infant tests and personality measures." Merrill Palmer Quarterly, 1972, 18, pp. 53-58.

Bracken, Bruce A.; Insko W. and Sabers, D. "Performance of Black and White Children on the Bracken Basic Concept Scale." Psychology in Schools, 1987, 24(1), pp. 22-27.

Bradley, Robert; Caldwell, Bettye M. and Elardo Richard. "The Relation of Infants' Home Environment to Mental Test Performance from Six to Thirty-six Months: A Longitudinal Analysis." Child Development, 1975, 46(1), pp. 71-76.

Brooks-Gunn, Jeanne; Duncan, Greg J.; Klebanov, Pamela K. and Sealand, Naomi. "Do Neighborhoods Influence Child and Adolescent Development?" American Journal of Sociology, 1993a, 99(2), pp. 353-95.

Brooks-Gunn, Jeanne; Duncan, Greg J. and Klebanov, Pamela K. "Economic Deprivation and Early-Childhood Development." Child Development, 1994, 65 (2), pp. 296-318.

. "Ethnic Differences in Children's Intelligence Test Scores: Role of Economic Deprivation, Home Environment and Maternal Characteristics." Child Development, 1996, 67(2), pp. 396-408.

Brooks-Gunn, Jeanne and Markman, Lisa B. "The Contribution of Parenting to Ethnic and Racial Gaps in School Readiness." The Future of Children, 2005, 15(1), pp. 139-68. 
Burkett, John; McMillen, Marilyn; Owings, Jeffery and Pinkerton, Daniel B.

"Statistics in Brief: Making the Cut: Who Meets Highly Selective College

Entrance Criteria?" Washington, DC: National Education Longitudinal Study (NELS), 1995.

Butler, Bruce V.; Goffeney, Barbara and Henderson, Norman B. "Negro-White, Male-Female Eight-month Developmental Scores Compared with Seven-Year WISC and Bender Test Scores." Child Development, 1971, 42, pp. 595-604.

Campbell, Frances A.; Nicholson, Janet E. and Ramey, Craig T. "The Predictive Power of the Bayley Scale of Infant Development and the Stanford-Binet Intelligence Test in a Relatively Constant Environment." Child Development, 1973, 44, pp. 790-95.

Campbell, Ernest Q.; Coleman, James S.; Hobson, Carol J.; McPartland, James; Mood, Alexander M.; Weinfeld, Frederic D. and York, Robert L. Equality of Educational Opportunity. Washington D.C.: U.S. Government Printing Office (GOP), 1966.

Chan Toy, Colleen; Deitz, Jean; Engel, Joyce M. and Wendel, Susan. "Performance of 6-Month-Old Asian American Infants on the Movement Assessment of Infants: A Descriptive Study." Physical \& Occupational Therapy in Pediatrics: A Quarterly Journal of Developmental Therapy, 19(3/4), pp.5-23, 2000.

Coley, Richard J. An Uneven Start: Indicators of Inequality in School Readiness. Policy Information Report. Educational Testing Service. Princeton, NJ: Educational Testing Service (ETS), 2002.

Colombo, John. Infant Cognition: Predicting Later Intellectual Functioning. Newbury Park, CA: Sage Publications Inc., 1993.

Cruse, Carol L.; Dumont, Ron; Price, Linda and Whelley, Peter. "The Relationship between the Differential Ability Scales (DAS) and the Wechsler Intelligence Scale for Children--Third Edition (WISC-III) for Students with Learning Disabilities." Psychology in the Schools, 1996, 33(3), pp. 203-09.

Dezoete, Anne J.; MacArthur, B.A. and Tuck, B. "Prediction of Bayley and StanfordBinet Scores with a group of very low birthweight children." Child Care, Health \& Development, 2003, 29(5), pp. 367-72.

Dickens, William T.; Flynn, James. "Heritability Estimates Versus Large Environmental Effects: The IQ Paradox Resolved." Psychological Review, 2001, 108(2): 346-369.

DiLalla, Lisabeth F.; Cypher, Lisa H.; Fagan, Joseph F.; Fulker, David W.; Haith, Marshall M.; Thompson, L.A.; Plomin, Robert and Phillips, Kay. "Infant Predictors of Preschool and Adult IQ: A Study of Infant Twins and Their Parents." Developmental Psychology, 1990, 26(5), pp. 759-69.

DiLalla, Lisabeth F.; Lovelace, Laneel and Molfese, Victoria J. "Perinatal, Home Environment and Infant Measures as Successful Predictors of Preschool cognitive and Verbal Abilities." International Journal of Behavioral Development, 1996, 19(1), pp. 101-19.

Enright, Mary K.; Jaskir, John and Lewis, Michael. "The Development of Mental Abilities in Infancy." Intelligence, 1986, 10, pp. 331-54.

Escalona, Sibylle K. and Moriarty, Alice. "Prediction of school age intelligence from infant tests." Child Development, 1961, 32(3), pp. 597-605.

Feldman, Judith F.; McCarton, Cecelia; Rose, Susan A. and Wallace, Ina.F. 
"Information Processing at 1 Year: Relation to Birth Status and Developmental Outcome During the First 5 Years." Developmental Psychology, 1991, 27(5), pp. 723-37.

Fryer, Roland and Levitt, Steven. "Understanding the Black-White Test Score Gap in the First Two Years of School." Review of Economics and Statistics, 2004 86, pp. 447-64.

. "The Black-White Test Score Gap Through Third Grade." American Law and Economic Review (forthcoming).

Gannon, D.R. "Relationships between 8-Mo. Performance on the Bayley Scale of Infant Development and 48-Mo. Intelligence and Concept Formation Scores." Psychological Reports, 1968, 23, pp. 1199-205.

Gravem, Howard; Ireton, Harold and Thwing, Edward. "Infant Mental Development and Neurological Status, Family Socioeconomic Status and Intelligence at Age Four." Child development, 1970, 41(4), pp. 937-45.

Hamilton, Barton H. and McManus, Brian P. "Competition, Insurance, and Quality in the Market for Advanced Infertility Treatment.” Mimeograph. St. Louis, MO: Washington University, John M. Olin School of Business, 2004.

Hernstein, Richard J. and Murray, Charles. The Bell Curve: Intelligence and Class Structure in American Life. New York: Free Press, 1994.

Honzik, Marjorie P. "Measuring mental abilities in infancy: The value and limitations," in M. Lewis, ed., Origins of Intelligence. 2nd ed. New York, NY: Plenum, 1983, pp. 67-105.

Humphreys, Lloyd G. "Trends in Levels of Academic Achievement of Blacks and Other Minorities." Intelligence, 1988, 12(3), pp. 231-60.

Jensen, Arthur R. Educability and Group Differences. New York: Free Press, 1973. . The G Factor: The Science of Mental Ability. Westport, CT: Praeger, 1998.

Karlberg, P.; Klackenberg, G.; Engström, L.; Klackenberg-Larsson, L.; Lichtenstein, H.; Stensson, J. and Svennberg, I. "The development of children in a Swedish urbancommunity: A prospective, longitudinal study: parts 1-VI." Acta Paediatrica Scandinavica Supplement, 1968, 187.

Kaufman, Alan S., and Kaufman, Nadeen L. K-ABC: Kaufman Assessment Battery for Children. Circle Pines, MN: American Guidance Services, 1983.

Kopp, Claire B. and McCall, Robert B. "Predicting later mental performance for normal, at-risk, and handicapped infants," in Paul B. Baltes and Orville G. Brim, Jr., eds., Life-span development and behavior. Vol 4. New York: Academic Press, 1990, pp. 31-61.

Krohn, Emily J. and Lamp, Robert E. "Current Validity of the Stanford-Binet Fourth Edition and K-ABC for Head Start Children." Journal of Psychology, 1989, 27(1), pp. 59-67.

Malina, Robert M. "Racial/ethnic variation in the motor development and performance of American children." Canadian Journal of Sport Sciences, 13(2), pp.136-43, 1988.

McGrath, Ellen; Bellinger, David C.; Newburger, Jane W.; Wypij, David and Rappaport, Leonard A. "Prediction of IQ and achievement at age 8 years from neurodevelopmental status at age 1 year in children with D-transposition of the great arteries." Pediatrics, 2004, 114 (5), pp. 572-76.

McGurk, Frank C. J.; Osborne, Robert T.; Osborne, Travis R.; and Shuey, Audrey 
M., eds. The Testing of Negro Intelligence. Vol. 2. Athens, GA: The Foundation for Human Understanding, 1982.

Myrianthopoulos, Ntinos C.; Naylor, Alfred F. and Willerman, Lee. "Intellectual Development of Children from Interracial Matings: Performance in Infancy and at 4 Years." Behavior Genetics, 1974, 4(1), pp. 83-90.

Naglieri, Jack A. "WISC-R and K-ABC Comparison for Matched Samples of Black and White Children." Journal of Social Psychology, 1986, 24(1), pp. 81-88.

Neisser, Ulric; Boodoo, Gwyneth; Bouchard, Thomas J.; Boykin, A. Wade; Brody, Nathan; Ceci, Stephen J.; Halpern, Diane F.; Loehlin, John C.; Perloff, Robert, Sternberg, Robert J. et al. "Intelligence: Knowns and unknowns." American Psychologist, 1996, 51, pp. 77-101.

Nisbett, Richard E. "Race, Gentics and IQ," in Christopher Jencks and Meredith Phillips, eds., The Black-White test score gap. Washington, DC: The Brookings Institute, 1998, pp. 86-102.

Nord, Christine; Andreassen, Carol; Branden, Laura; Dulaney, Rick; Edwards, Brad; Elmore, Anne; Flanagan, Kristin Denton; Fletcher, Philip; Green, Jim; Hilpert, Richard et al. Early Childhood Longitudinal Study, Birth Cohort (ECLS-B), User's Manual for the ECLS-B Nine-Month Public-Use Data File and Electronic Code Book. Washington, DC: U.S. Department of Education, NCES, 2004.

Phillips, Meredith; Brooks-Gunn, Jeanne; Crane, Jonathan; Duncan, Greg J. and Klebanov, Pamela K. "Family Background, Parenting Practices, and the BlackWhite Test Score Gap," in Christopher Jencks and Meredith Phillips, eds., The Black-White test score gap. Washington, DC: The Brookings Institute, 1998, pp. 103-45

Phillips, Meredith. "Understanding Ethnic Differences in Academic Achievement: Empirical Lessons from National Data," in David W. Grissmer and Michael J. Ross, eds., Analytic Issues in the Assessment of Student Achievement. Washington, DC: U.S. Department of Education, National Center for Education Statistics (NCES), 2000, pp 103-32.

Rose, Susan A. and Wallace, Ina F. "Visual recognition memory: a predictor of later cognitive functioning in preterms." Child Development, 1985, 56 (4), pp. 843-52.

Rushton, Philippe J. "Race and crime: international data for 1989-1990." Psychological Reports, 1995, 76(1), pp. 307-12.

Rushton, J. Philippe and Arthur Jensen. "Thirty Years of Research on Race Differences in Cognitive Ability." Psychology, Public Policy, and Law, 2005, 11(2), pp. 235-94.

Scarr, Sandra. Race, Social Class and Individual Differences in I.Q. Mahwah, NJ: Lawrence Erlbaum Associates, 1981.

Scott, R. and Sinclair, D. "Ethnic-related cognitive profiles of black and white preschool children." Homo- Journal of Comparative Human Biology, 1997, 28, pp.116-20.

Shuey, Audrey M. The Testing of Negro Intelligence. Lynchburg, VA: J.P. Bell Company, 1958.

White, Roberta, Richard Cambell, Patricia Janulewicz. Neuropsychological Assessments in Children from a Longitudinal Perspective for the National Children's Study. Battelle Memorial Institute, 2004.

Wilson, Ronald S. “The Louisville Twin Study: Developmental Synchronies in 
Behavior." Child Development, 1983, 54(2), pp. 293-316.

Yeates, K. O.; MacPhee, D.; Campbell, F. A. and Ramey, C. T. "Maternal IQ and home environment as determinants of early childhood intellectual competence: Developmental analysis." Developmental Psychology, 1983, 19, pp. 731-9. 
Figure 1: The Correlation between Bayley Scores and Later IQ

Figure 1

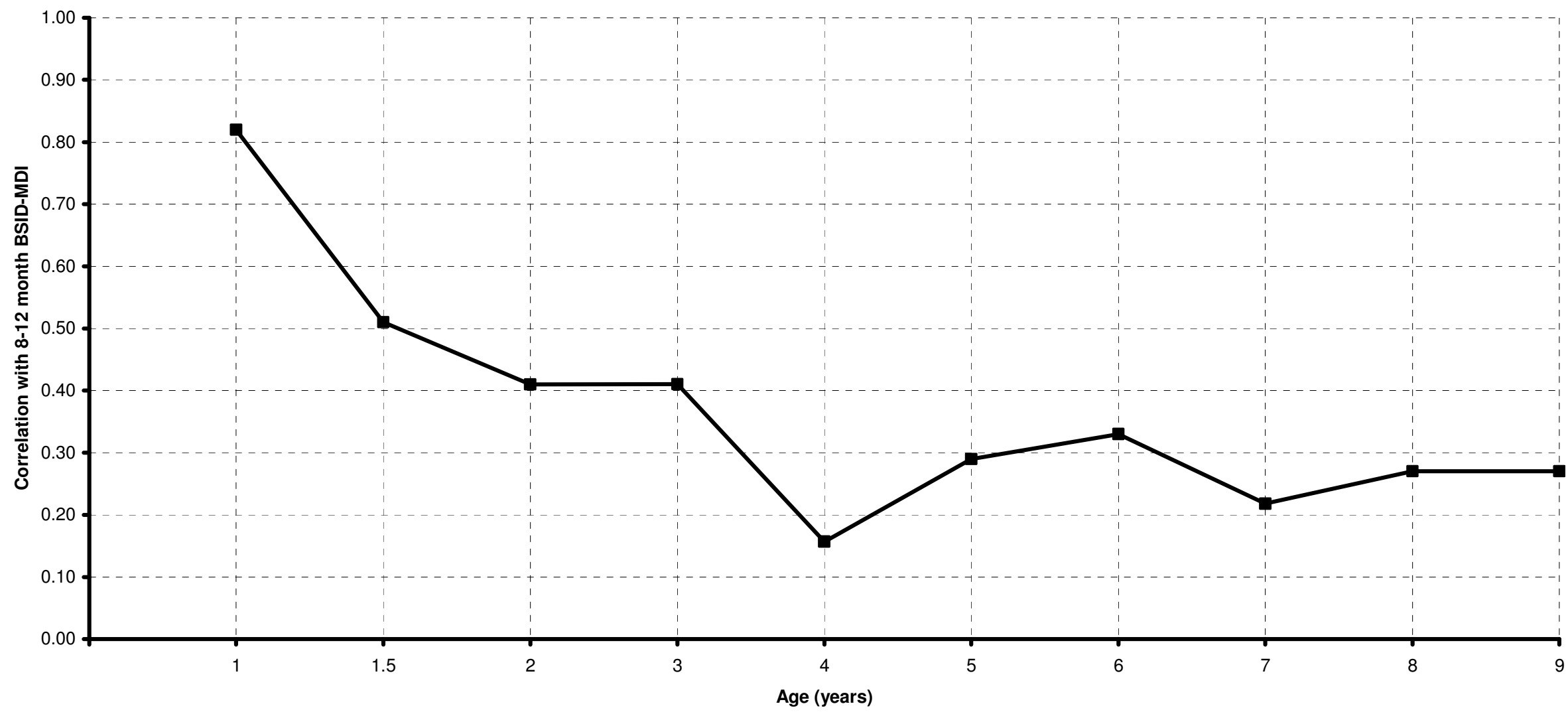

Notes: See Appendix Table 1 for a list of sources from which the correlations are based. Each is a (sample size) weighted average of the correlations found across all relevant studies. 
Figure 2: The Distribution of Bayley Scores, by Race

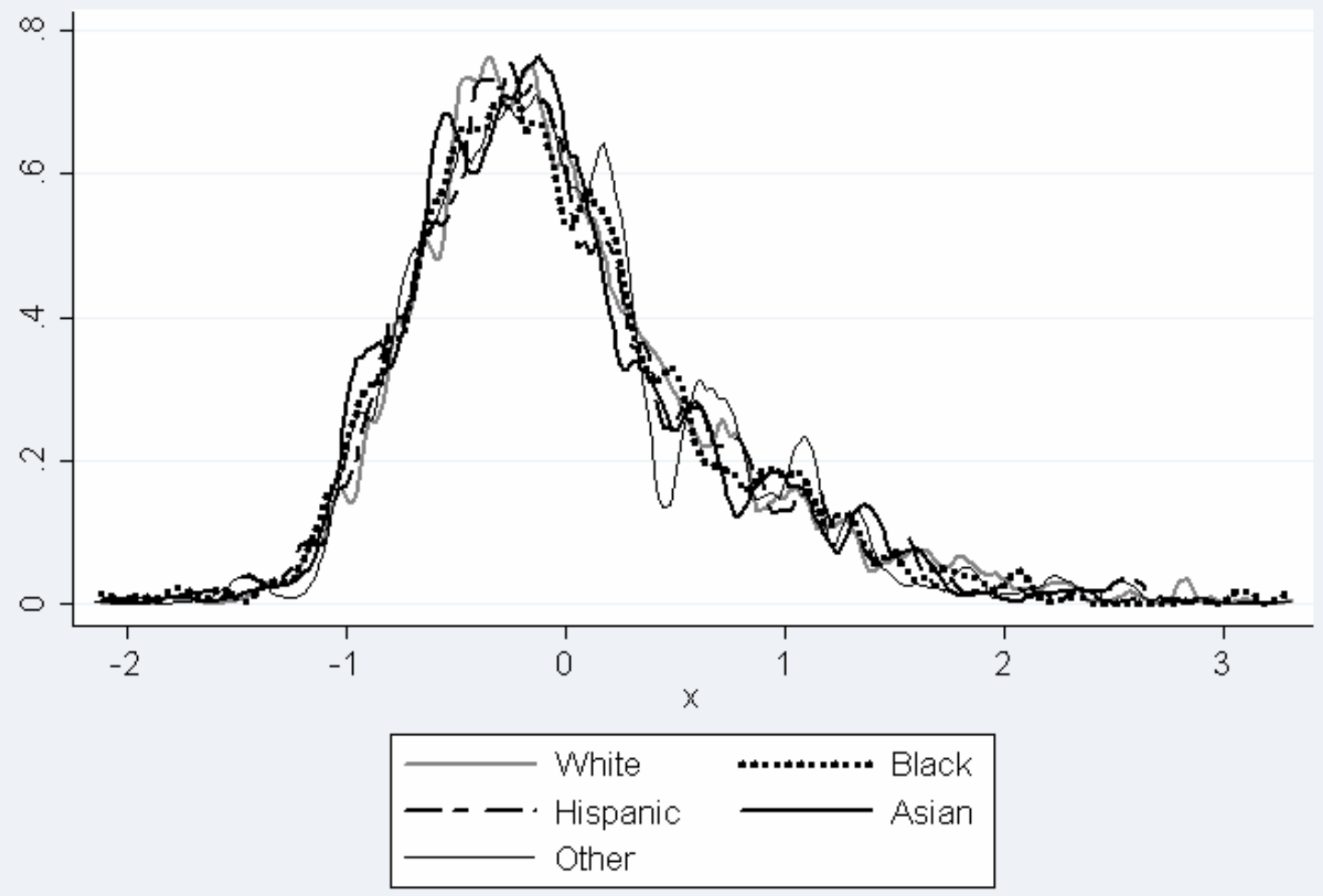


Table 1: Summary statistics

\begin{tabular}{|c|c|c|c|c|c|c|}
\hline Variables & All Races & White & Black & Hispanic & Asian & Other \\
\hline \multicolumn{7}{|l|}{ Cognitive Development } \\
\hline Mental function composite score & $\begin{array}{c}0.0002 \\
(0.9996)\end{array}$ & $\begin{array}{c}0.0182 \\
(0.9426)\end{array}$ & $\begin{array}{c}-0.0258 \\
(0.8951)\end{array}$ & $\begin{array}{l}-0.0185 \\
(0.9156)\end{array}$ & $\begin{array}{c}-0.0513 \\
(0.9551)\end{array}$ & $\begin{array}{c}0.0065 \\
(1.1528)\end{array}$ \\
\hline \multicolumn{7}{|l|}{ Demographics } \\
\hline age & $\begin{array}{c}10.2677 \\
(1.9362)\end{array}$ & $\begin{array}{c}10.2379 \\
(1.7914)\end{array}$ & $\begin{array}{r}10.2920 \\
(1.7777)\end{array}$ & $\begin{array}{c}10.2983 \\
(1.822)\end{array}$ & $\begin{array}{c}10.3397 \\
(1.8556)\end{array}$ & $\begin{array}{l}10.3285 \\
(2.4305)\end{array}$ \\
\hline female & $\begin{array}{c}0.4892 \\
(0.6835)\end{array}$ & $\begin{array}{c}0.4848 \\
(0.6401)\end{array}$ & $\begin{array}{c}0.4855 \\
(0.6232)\end{array}$ & $\begin{array}{l}0.4987 \\
(0.627)\end{array}$ & $\begin{array}{c}0.4708 \\
(0.6593)\end{array}$ & $\begin{array}{c}0.5130 \\
(0.8661)\end{array}$ \\
\hline \multicolumn{7}{|l|}{ region: } \\
\hline northeast & $\begin{array}{c}0.1684 \\
(0.5513)\end{array}$ & $\begin{array}{c}0.1818 \\
(0.5355)\end{array}$ & $\begin{array}{c}0.1575 \\
(0.4856)\end{array}$ & $\begin{array}{c}0.1470 \\
(0.4609)\end{array}$ & $\begin{array}{c}0.1974 \\
(0.6072)\end{array}$ & $\begin{array}{c}0.1428 \\
(0.7097)\end{array}$ \\
\hline midwest & $\begin{array}{c}0.2223 \\
(0.5511)\end{array}$ & $\begin{array}{l}0.2818 \\
(0.558)\end{array}$ & $\begin{array}{c}0.2092 \\
(0.4997)\end{array}$ & $\begin{array}{c}0.1076 \\
(0.3649)\end{array}$ & $\begin{array}{c}0.1583 \\
(0.4284)\end{array}$ & $\begin{array}{c}0.2527 \\
(0.7413)\end{array}$ \\
\hline south & $\begin{array}{c}0.3675 \\
(0.6566)\end{array}$ & $\begin{array}{c}0.3601 \\
(0.6132)\end{array}$ & $\begin{array}{c}0.5569 \\
(0.6237)\end{array}$ & $\begin{array}{c}0.3147 \\
(0.5854)\end{array}$ & $\begin{array}{c}0.1876 \\
(0.5275)\end{array}$ & $\begin{array}{c}0.2906 \\
(0.8)\end{array}$ \\
\hline west & $\begin{array}{c}0.2418 \\
(0.5779)\end{array}$ & $\begin{array}{c}0.1763 \\
(0.4788)\end{array}$ & $\begin{array}{c}0.0765 \\
(0.3479)\end{array}$ & $\begin{array}{c}0.4307 \\
(0.6199)\end{array}$ & $\begin{array}{l}0.4567 \\
(0.651)\end{array}$ & $\begin{array}{c}0.3140 \\
(0.7526)\end{array}$ \\
\hline \multicolumn{7}{|l|}{ Home environment } \\
\hline \multicolumn{7}{|l|}{ SES quintiles: } \\
\hline 1st quintile (lowest) & $\begin{array}{c}0.2000 \\
(0.5346)\end{array}$ & $\begin{array}{c}0.0850 \\
(0.3471)\end{array}$ & $\begin{array}{c}0.3424 \\
(0.5894)\end{array}$ & $\begin{array}{c}0.3789 \\
(0.6086)\end{array}$ & $\begin{array}{c}0.1021 \\
(0.4213)\end{array}$ & $\begin{array}{c}0.1753 \\
(0.6472)\end{array}$ \\
\hline 2nd quintile & $\begin{array}{c}0.1999 \\
(0.5391)\end{array}$ & $\begin{array}{c}0.1572 \\
(0.4543)\end{array}$ & $\begin{array}{c}0.2408 \\
(0.5325)\end{array}$ & $\begin{array}{c}0.2633 \\
(0.5529)\end{array}$ & $\begin{array}{c}0.1417 \\
(0.5695)\end{array}$ & $\begin{array}{c}0.2622 \\
(0.7867)\end{array}$ \\
\hline 3rd quintile & $\begin{array}{c}0.1999 \\
(0.5456)\end{array}$ & $\begin{array}{c}0.2087 \\
(0.5174)\end{array}$ & $\begin{array}{l}0.2091 \\
(0.511)\end{array}$ & $\begin{array}{l}0.1817 \\
(0.482)\end{array}$ & $\begin{array}{c}0.1436 \\
(0.4305)\end{array}$ & $\begin{array}{c}0.2097 \\
(0.6977)\end{array}$ \\
\hline 4th quintile & $\begin{array}{c}0.2005 \\
(0.5589)\end{array}$ & $\begin{array}{l}0.2624 \\
(0.569)\end{array}$ & $\begin{array}{c}0.1289 \\
(0.4212)\end{array}$ & $\begin{array}{c}0.1146 \\
(0.3985)\end{array}$ & $\begin{array}{c}0.1538 \\
(0.4298)\end{array}$ & $\begin{array}{c}0.2047 \\
(0.6962)\end{array}$ \\
\hline 5th quintile (highest) & $\begin{array}{c}0.1997 \\
(0.5554)\end{array}$ & $\begin{array}{c}0.2868 \\
(0.5849)\end{array}$ & $\begin{array}{l}0.0788 \\
(0.339)\end{array}$ & $\begin{array}{c}0.0615 \\
(0.3013)\end{array}$ & $\begin{array}{c}0.4588 \\
(0.6531)\end{array}$ & $\begin{array}{c}0.1480 \\
(0.5923)\end{array}$ \\
\hline number of siblings & $\begin{array}{c}0.9848 \\
(1.4761)\end{array}$ & $\begin{array}{c}0.9568 \\
(1.2918)\end{array}$ & $\begin{array}{l}1.1316 \\
(1.543)\end{array}$ & $\begin{array}{c}0.9899 \\
(1.46)\end{array}$ & $\begin{array}{c}0.7783 \\
(1.2742)\end{array}$ & $\begin{array}{c}0.9754 \\
(1.8726)\end{array}$ \\
\hline present & $\begin{array}{c}0.7892 \\
(0.5352)\end{array}$ & $\begin{array}{c}0.8833 \\
(0.4051)\end{array}$ & $\begin{array}{c}0.4111 \\
(0.6171)\end{array}$ & $\begin{array}{c}0.7901 \\
(0.5085)\end{array}$ & $\begin{array}{c}0.9212 \\
(0.4085)\end{array}$ & $\begin{array}{c}0.7322 \\
(0.7824)\end{array}$ \\
\hline one biological parent present & $\begin{array}{c}0.1938 \\
(0.5155)\end{array}$ & $\begin{array}{c}0.0960 \\
(0.3716)\end{array}$ & $\begin{array}{c}0.5793 \\
(0.6185)\end{array}$ & $\begin{array}{c}0.1950 \\
(0.4939)\end{array}$ & $\begin{array}{c}0.0754 \\
(0.4058)\end{array}$ & $\begin{array}{c}0.2504 \\
(0.7737)\end{array}$ \\
\hline biological parent present & $\begin{array}{c}0.0114 \\
(0.1455)\end{array}$ & $\begin{array}{c}0.0142 \\
(0.1508)\end{array}$ & $\begin{array}{c}0.0067 \\
(0.1007)\end{array}$ & $\begin{array}{c}0.0094 \\
(0.1109)\end{array}$ & $\begin{array}{c}0.0015 \\
(0.0349)\end{array}$ & $\begin{array}{c}0.0106 \\
(0.1715)\end{array}$ \\
\hline other parental configuration & $\begin{array}{c}0.0056 \\
(0.1042)\end{array}$ & $\begin{array}{c}0.0065 \\
(0.0979)\end{array}$ & $\begin{array}{c}0.0030 \\
(0.0578)\end{array}$ & $\begin{array}{c}0.0054 \\
(0.1097)\end{array}$ & $\begin{array}{c}0.0020 \\
(0.0424)\end{array}$ & $\begin{array}{l}0.0069 \\
(0.056)\end{array}$ \\
\hline mother's age & $\begin{array}{l}27.2587 \\
(8.3082)\end{array}$ & $\begin{array}{l}28.3941 \\
(7.6037)\end{array}$ & $\begin{array}{l}25.1252 \\
(7.5755)\end{array}$ & $\begin{array}{c}26.0201 \\
(7.334)\end{array}$ & $\begin{array}{l}29.4158 \\
(7.2416)\end{array}$ & $\begin{array}{c}25.8535 \\
(10.6263)\end{array}$ \\
\hline parent as teacher score & $\begin{array}{c}29.6979 \\
(17.4207)\end{array}$ & $\begin{array}{c}31.2523 \\
(15.4744)\end{array}$ & $\begin{array}{c}28.4809 \\
(16.1934)\end{array}$ & $\begin{array}{l}27.3848 \\
(16.909)\end{array}$ & $\begin{array}{c}27.0006 \\
(19.1218)\end{array}$ & $\begin{array}{r}29.9106 \\
(23.2064)\end{array}$ \\
\hline
\end{tabular}




\begin{tabular}{|c|c|c|c|c|c|c|}
\hline \multicolumn{7}{|l|}{ Prenatal environment } \\
\hline \multicolumn{7}{|l|}{ birthweight: } \\
\hline \multirow{2}{*}{$<1500$} & 0.0127 & 0.0102 & 0.0240 & 0.0121 & 0.0072 & 0.0154 \\
\hline & $(0.0445)$ & $(0.0348)$ & $(0.0635)$ & $(0.0419)$ & $(0.054)$ & $(0.0749)$ \\
\hline \multirow[t]{2}{*}{$>1500 \&<2500$} & 0.0621 & 0.0557 & 0.0998 & 0.0550 & 0.0651 & 0.0601 \\
\hline & $(0.1934)$ & $(0.1616)$ & $(0.2524)$ & $(0.1773)$ & $(0.2618)$ & $(0.2609)$ \\
\hline \multirow[t]{2}{*}{$>2500 \&<3500$} & 0.5451 & 0.5123 & 0.6023 & 0.5669 & 0.6832 & 0.5458 \\
\hline & $(0.6776)$ & $(0.6391)$ & $(0.5985)$ & $(0.6153)$ & $(0.6079)$ & $(0.8588)$ \\
\hline \multirow[t]{2}{*}{3500 or more } & 0.3796 & 0.4212 & 0.2732 & 0.3656 & 0.2445 & 0.3778 \\
\hline & $(0.6737)$ & $(0.6367)$ & $(0.5794)$ & $(0.608)$ & $(0.5815)$ & $(0.8539)$ \\
\hline \multirow[t]{2}{*}{ Percent premature } & 0.1167 & 0.1016 & 0.1685 & 0.1169 & 0.0948 & 0.1534 \\
\hline & $(0.3677)$ & $(0.3186)$ & $(0.412)$ & $(0.3492)$ & $(0.3246)$ & $(0.5675)$ \\
\hline \multicolumn{7}{|c|}{ Days premature (conditional on being } \\
\hline \multirow[t]{2}{*}{ premature) } & 21.1239 & 21.0457 & 22.7998 & 20.2129 & 17.4876 & 21.4877 \\
\hline & (23.6229) & $(24.2518)$ & (23.5968) & $(19.9711)$ & $(13.4793)$ & (32.8074) \\
\hline \multicolumn{7}{|l|}{ multiple birth: } \\
\hline \multirow[t]{2}{*}{ singleton } & 0.9668 & 0.9624 & 0.9693 & 0.9768 & 0.9786 & 0.9452 \\
\hline & $(0.1007)$ & $(0.0997)$ & $(0.091)$ & $(0.0749)$ & $(0.1175)$ & $(0.1813)$ \\
\hline \multirow[t]{2}{*}{ twin } & 0.0298 & 0.0347 & 0.0300 & 0.0214 & 0.0197 & 0.0252 \\
\hline & $(0.0927)$ & $(0.0925)$ & $(0.0882)$ & $(0.0718)$ & $(0.1125)$ & $(0.113)$ \\
\hline \multirow[t]{2}{*}{ higher order } & 0.0018 & 0.0028 & 0.0007 & 0.0007 & 0.0016 & 0.0005 \\
\hline & $(0.0296)$ & $(0.0337)$ & $(0.0214)$ & $(0.0102)$ & $(0.0332)$ & $(0.0118)$ \\
\hline
\end{tabular}

NOTES: The entries are means and standard deviations of child-level data for those children in ECLS-B who do not have missing values for test scores. Test scores are a mental composite score, normalized to have a mean of 0 and a standard deviation of 1 . The category "White" includes only non-Hispanic Whites. Precise definitions of the variables are provided in the data appendix. The SES measure incorporates information on parental education, occupational status, and family income. Days premature is conditional on being premature. The total number of children in the sample who receive a positive weight in the estimation is 10,132 . In all cases, sample weights provided with ECLS are used in the calculations. 
Table 2: Estimating Group Differences in the Mental Function Composite Score

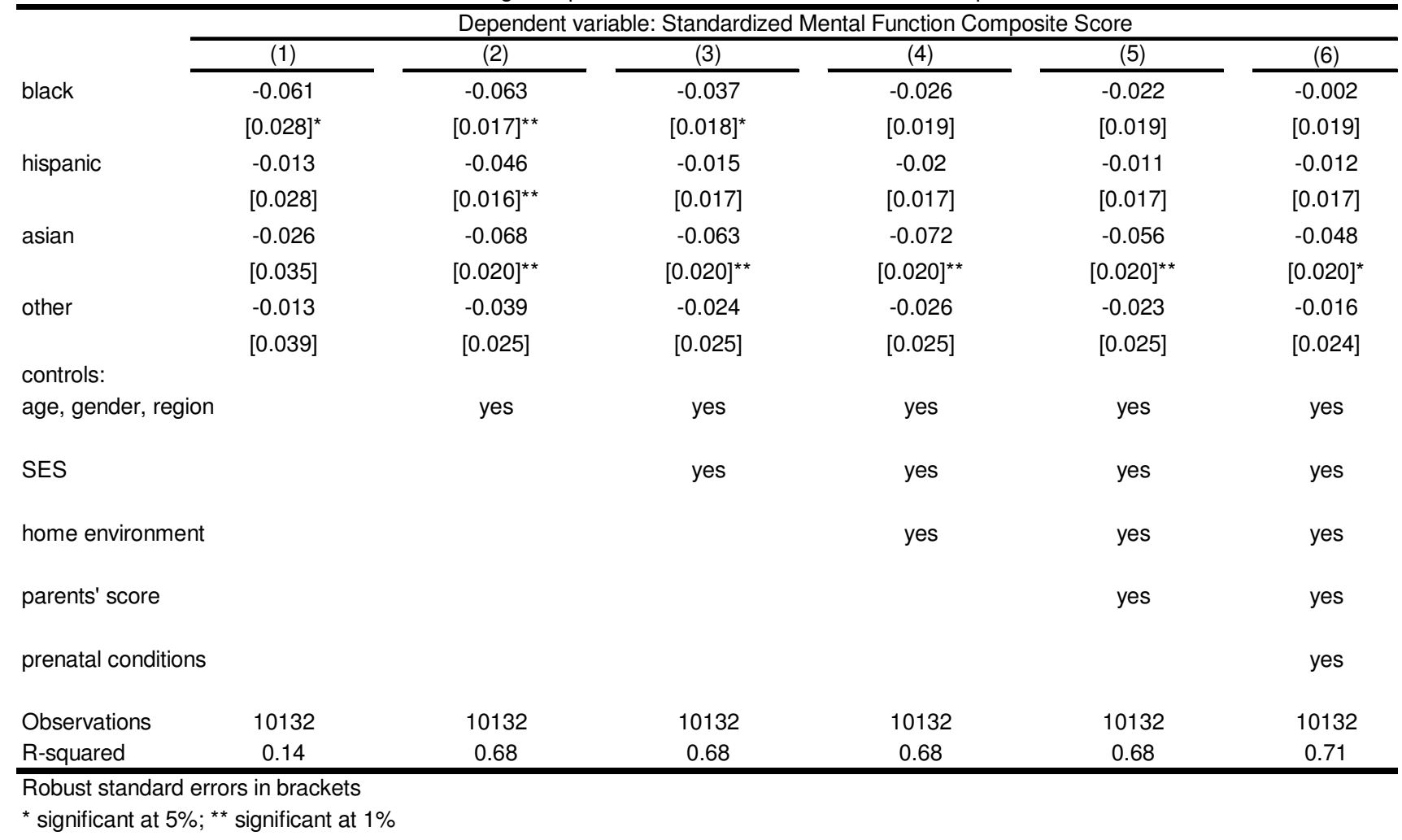

NOTES: The dependent variable is the mental composite score, which are normalized to have a mean of 0 and a standard deviation of 1 in the full, unweighted sample. Non-Hispanic Whites are the omitted race category, so all of the race coefficients are gaps relative to that group. The unit of observation is a child. Standard errors are in parentheses. Estimation is done using weighted least squares, using sample weights provided in the data set. In addition to the variables included in the table, indicator variables for children with missing values on each covariate are also included in the regressions. All regressions include interviewer fixed effects. 
Table 3: Sensitivity Analysis of Group Differences in Mental Function Composite Score

\begin{tabular}{|c|c|c|c|c|}
\hline & black & hispanic & asian & other \\
\hline \multirow[t]{2}{*}{ baseline } & -0.002 & -0.012 & -0.048 & -0.016 \\
\hline & [0.019] & {$[0.017]$} & {$[0.020]^{\star}$} & [0.024] \\
\hline \multirow[t]{2}{*}{ unweighted } & 0.020 & 0.000 & -0.061 & 0.007 \\
\hline & {$[0.014]$} & [0.013] & {$[0.015]^{\star *}$} & [0.015] \\
\hline \multirow[t]{2}{*}{ males only } & -0.018 & 0.007 & -0.024 & -0.041 \\
\hline & [0.028] & [0.023] & [0.030] & [0.039] \\
\hline \multirow[t]{2}{*}{ females only } & 0.021 & -0.012 & -0.073 & 0.004 \\
\hline & [0.024] & {$[0.025]$} & {$[0.027]^{\star \star}$} & [0.029] \\
\hline \multirow[t]{2}{*}{ SES quintile 1} & -0.046 & -0.042 & -0.143 & 0.001 \\
\hline & [0.049] & [0.044] & {$[0.062]^{*}$} & [0.059] \\
\hline \multirow[t]{2}{*}{ SES quintile 2} & -0.045 & -0.059 & -0.095 & 0.028 \\
\hline & [0.035] & {$[0.036]$} & [0.055] & [0.066] \\
\hline \multirow[t]{2}{*}{ SES quintile 3} & -0.006 & 0.000 & -0.019 & -0.060 \\
\hline & [0.042] & {$[0.036]$} & [0.047] & [0.043] \\
\hline \multirow[t]{2}{*}{ SES quintile 4} & 0.028 & 0.022 & -0.108 & -0.028 \\
\hline & {$[0.045]$} & [0.039] & {$[0.050]^{\star}$} & [0.042] \\
\hline \multirow[t]{2}{*}{ SES quintile 5} & 0.043 & -0.008 & -0.017 & -0.034 \\
\hline & {$[0.051]$} & [0.048] & {$[0.035]$} & [0.045] \\
\hline \multirow[t]{2}{*}{ if both biological parents present } & 0.009 & -0.020 & -0.034 & 0.009 \\
\hline & {$[0.024]$} & {$[0.019]$} & {$[0.020]$} & [0.027] \\
\hline \multirow[t]{2}{*}{ if a biological parent not present } & 0.000 & 0.021 & -0.168 & -0.043 \\
\hline & {$[0.035]$} & {$[0.039]$} & {$[0.075]^{*}$} & [0.049] \\
\hline \multirow[t]{2}{*}{ if northwest } & -0.010 & -0.010 & 0.018 & -0.090 \\
\hline & {$[0.045]$} & {$[0.046]$} & {$[0.060]$} & [0.088] \\
\hline \multirow[t]{2}{*}{ if midwest } & 0.113 & 0.033 & 0.019 & 0.029 \\
\hline & {$[0.041]^{\star *}$} & {$[0.040]$} & [0.048] & [0.044] \\
\hline \multirow[t]{2}{*}{ if south } & -0.053 & -0.037 & -0.070 & -0.031 \\
\hline & {$[0.026]^{*}$} & {$[0.027]$} & {$[0.035]^{\star}$} & [0.042] \\
\hline \multirow[t]{2}{*}{ if west } & 0.063 & -0.005 & -0.076 & -0.009 \\
\hline & [0.052] & {$[0.030]$} & {$[0.031]^{*}$} & [0.036] \\
\hline \multirow[t]{2}{*}{ if urban, inside UA } & 0.011 & 0.010 & -0.037 & -0.013 \\
\hline & {$[0.021]$} & {$[0.019]$} & [0.021] & [0.026] \\
\hline \multirow[t]{2}{*}{ if urban, outside UC } & -0.050 & -0.072 & -0.015 & -0.030 \\
\hline & [0.082] & [0.054] & {$[0.076]$} & [0.072] \\
\hline \multirow[t]{2}{*}{ if rural } & -0.034 & -0.117 & -0.045 & -0.041 \\
\hline & {$[0.057]$} & {$[0.069]$} & [0.224] & [0.053] \\
\hline \multirow[t]{2}{*}{ if normal birthweight } & -0.008 & -0.012 & -0.047 & -0.023 \\
\hline & {$[0.020]$} & {$[0.018]$} & {$[0.021]^{*}$} & [0.026] \\
\hline if moderately low birthweight & -0.005 & -0.030 & -0.079 & -0.043 \\
\hline & {$[0.041]$} & {$[0.040]$} & [0.059] & [0.063] \\
\hline if very low birthweight & 0.071 & 0.009 & -0.212 & -0.079 \\
\hline & {$[0.046]$} & [0.054] & [0.149] & [0.101] \\
\hline controlling for motor skills & -0.034 & -0.005 & -0.066 & -0.037 \\
\hline & {$[0.018]$} & {$[0.016]$} & {$[0.018]^{\star *}$} & [0.023] \\
\hline age $<9$ months & -0.059 & -0.046 & -0.054 & 0.037 \\
\hline & {$[0.038]$} & [0.033] & {$[0.038]$} & [0.048] \\
\hline 9 months $<=$ age $<10$ months & -0.005 & 0.000 & -0.019 & 0.002 \\
\hline & {$[0.025]$} & {$[0.024]$} & [0.025] & [0.032] \\
\hline 10 months $<=$ age $<11$ months & 0.024 & -0.022 & -0.040 & -0.002 \\
\hline & {$[0.034]$} & [0.032] & [0.035] & [0.047] \\
\hline 11 months $<=$ age $<12$ months & 0.003 & 0.014 & -0.105 & -0.044 \\
\hline & {$[0.064]$} & {$[0.063]$} & {$[0.070]$} & [0.120] \\
\hline age $>=12$ months & -0.014 & 0.039 & -0.038 & -0.071 \\
\hline & [0.072] & {$[0.063]$} & {$[0.066]$} & [0.081] \\
\hline
\end{tabular}


NOTES: Specifications in this table are variations on those reported in column (6) of Table 2. Only the race coefficients are reported. The top row simply reproduces the baseline results in column (6) of Table 2 . The remaining rows correspond to different weights, socio-economic quintiles and other particular subsets of the data. For further details of the baseline specification, see the notes to Table 2. 


\begin{tabular}{|c|c|c|c|c|c|}
\hline & explores objects & $\begin{array}{l}\text { explores objects } \\
\text { purposefully }\end{array}$ & babbles & early problem & uses words \\
\hline \multirow[t]{2}{*}{ black } & -0.0007 & -0.0012 & 0.0022 & -0.0027 & -0.0033 \\
\hline & {$[0.0005]$} & {$[0.0039]$} & {$[0.0047]$} & {$[0.0046]$} & [0.0039] \\
\hline \multirow[t]{2}{*}{ hispanic } & -0.0006 & -0.0039 & -0.0021 & -0.0013 & -0.0013 \\
\hline & [0.0004] & [0.0039] & {$[0.0043]$} & {$[0.0041]$} & [0.0033] \\
\hline \multirow[t]{2}{*}{ asian } & -0.0004 & -0.0054 & -0.0128 & -0.0088 & -0.0048 \\
\hline & {$[0.0004]$} & [0.0044] & {$[0.0053]^{*}$} & {$[0.0047]$} & {$[0.0030]$} \\
\hline \multirow[t]{2}{*}{ other } & -0.0002 & -0.0015 & -0.0031 & -0.0041 & -0.0031 \\
\hline & {$[0.0005]$} & [0.0051] & {$[0.0064]$} & [0.0061] & {$[0.0046]$} \\
\hline \multicolumn{6}{|l|}{ controls: } \\
\hline age, gender, region, mother's age & yes & yes & yes & yes & yes \\
\hline SES & yes & yes & yes & yes & yes \\
\hline home environment & yes & yes & yes & yes & yes \\
\hline parents' score & yes & yes & yes & yes & yes \\
\hline prenatal conditions & yes & yes & yes & yes & yes \\
\hline mean of dependent variable & 0.9938 & 0.9058 & 0.5471 & 0.0906 & 0.0317 \\
\hline sd of dependent variable & $(0.0145)$ & $(0.1555)$ & $(0.268)$ & $(0.2172)$ & $(0.1399)$ \\
\hline Observations & 10132 & 10132 & 10132 & 10132 & 10132 \\
\hline R-squared & 0.21 & 0.43 & 0.73 & 0.64 & 0.44 \\
\hline
\end{tabular}

NOTES: Entries are unadjusted mean scores on specific components of the mental composite score. They are proficient probability scores, which are constructed using IRT scores and provide the probability of mastery of a specific skill set. 
Table 5: Estimates Used in Calibrating the Model

\begin{tabular}{lccc}
\hline Measure & Algebraic Representation & Value Used & Source \\
\hline $\begin{array}{l}\text { Internal Reliability of BSID } \\
\begin{array}{l}\text { Internal Reliability of later test } \\
\text { scores }\end{array}\end{array}$ & 0.80 & Andreassen and Fletcher (2005) \\
$\begin{array}{l}\text { Correlation between BSID } \\
\text { and later test scores }\end{array}$ & $\operatorname{corr}\left(S_{i l}, S_{i l}^{\prime}\right)$ & 0.94 & White et. al. 2004 \\
$\begin{array}{l}\text { Correlation between later IQ } \\
\text { tests when taken three years } \\
\text { apart }\end{array}$ & $\operatorname{corr}\left(S_{i l}^{\prime}, S_{i l+3}^{\prime}\right)$ & 0.30 & Figure 2 \\
$\begin{array}{l}\text { Black-White test score gap } \\
\text { on BSID }\end{array}$ & $\bar{S}_{W, e}-\bar{S}_{B, e}$ & 0.60 & Cruse et.al. 1996 \\
$\begin{array}{l}\text { Black-White test score gap } \\
\text { on later tests }\end{array}$ & $\bar{S}_{W, l}-\bar{S}_{B, l}$ & 0.06 & Table 2 \\
$\begin{array}{l}\text { Correlation between parental } \\
\text { IQ and BSID }\end{array}$ & $\operatorname{corr}\left(S_{i e}, S_{i P}\right)$ & 1.00 & Rushton and Jensen (2005) \\
& & 0.36 & Yeates et al. 1983 \\
$\begin{array}{l}\text { Correlation between parental } \\
\text { IQ and child IQ on later tests }\end{array}$ & $\operatorname{corr}\left(S_{i l}, S_{P}\right)$ & & \\
\hline
\end{tabular}


Appendix Table 1: Literature on the Relationship Between Bayley Scores and Future IQ

\begin{tabular}{|c|c|c|c|c|}
\hline & Age of Bayley & & & \\
\hline Author(s) & (months) & Future IQ Test and Age (years) & Correlation & $\mathbf{N}$ \\
\hline Gannon, 1968 & 8 & Stanford-Binet at age 4 & 0.13 & 371 \\
\hline $\begin{array}{l}\text { Butler, Goffeney and } \\
\text { Henderson and, } 1971\end{array}$ & 8 & Wechsler Intelligence Scale for Children at age 7 & 0.19 & 626 \\
\hline $\begin{array}{l}\text { Ireton, Gravem and Thwig, } \\
1970\end{array}$ & 8 & Stanford-Binet at age 4 & 0.25 & 500 \\
\hline $\begin{array}{l}\text { Myrianthopoulos, Naylor and } \\
\text { Willerman, } 1974\end{array}$ & 8 & Stanford-Binet at age 4 & 0.22 & 129 \\
\hline Bayley, 1955 & $9 \& 12$ & Mean 16-18 IQ & $0.32,0.30$ & 45 \\
\hline Ramey et al., 1973 & 9 to 12 & Stanford-Binet at age 3 & 0.71 & 11 \\
\hline \multirow[t]{3}{*}{ Wilson, 1983} & $9 \& 12$ & Stanford-Binet at age 3 & 0.38 & 340 \\
\hline & & 6 Wechsler Preschool and Primary Scale of Intelligence at ages 4, 5, and & $\begin{array}{l}0.29,0.35 \\
\quad 0.33\end{array}$ & 340 \\
\hline & & Wechsler Intelligence Scale for Children at ages 7, 8, and 9 & $\begin{array}{l}0.27,0.27 \\
\quad 0.27\end{array}$ & 340 \\
\hline $\begin{array}{l}\text { Bradley, Caldwell and } \\
\text { Elardo } 1975\end{array}$ & 12 & Stanford-Binet at age 3 & 0.32 & 77 \\
\hline Barnard et al.1982 & 12 & Stanford-Binet at age 4 & 0.21 & 156 \\
\hline $\begin{array}{l}\text { Enright, Jaskir and Lewis, } \\
1986\end{array}$ & 12 & Stanford-Binet at age 3 & 0.12 & 116 \\
\hline DiLalla et al., 1990 & 12 & Stanford-Binet at age 3 & 0.32 & 40 \\
\hline Rose et al., 1991 & 12 & Stanford-Binet at ages 3 and 4 & $0.30,0.22$ & 40 \\
\hline $\begin{array}{l}\text { DiLalla, Lovelace and } \\
\text { Molfese, } 1996\end{array}$ & 12 & Stanford-Binet at ages 3 and 4 & $.17, .14$ & 94 \\
\hline Acheson and Molfese, 1997 & 12 & Stanford-Binet at ages 3,4 and 5 & $.14, .15, .06$ & 89 \\
\hline
\end{tabular}

NOTES: To generate relevant literature, Pubmed, EBSCOhost and JSTOR were searched for all years. Keywords used for the search included, "Bayley Scale of Infant Development," "BSID, "predictive power," "correlation," and "IQ" - which generated a list of roughly 2,000 references. Among these, we selected according to the following criteria. (1) the test of infant cognition was the Bayley Scale of Infant Development (BSID); (2) The "future" test age was administered more than 2 years after the infant measure was taken (correlations at 12 and 18 months were obtained from Wilson 1983); (3) the initial BSID had to be administered between 6 and 12 months of age; (4) the sample had to be "representative" - we omitted studies with subjects afflicted by major health issues (e.g., heart disease, Down syndrome, mental retardation) or severe complications at birth (i.e. pre-term, mother used drugs or alcohol); and (5) only studies done in the United States were used. The final compilation contained 14 studies. 
Appendix Table 2: Estimating Group Differences in the Mental Function Composite Score

\begin{tabular}{|c|c|c|c|c|c|c|}
\hline & \multicolumn{6}{|c|}{ Dependent variable: Standardized Mental Function Composite Score } \\
\hline & $(1)$ & $(2)$ & $(3)$ & $(4)$ & $(5)$ & $(6)$ \\
\hline \multirow[t]{2}{*}{ Black } & -0.061 & -0.063 & -0.037 & -0.026 & -0.022 & -0.002 \\
\hline & {$[0.028]^{*}$} & {$[0.017]^{\star *}$} & {$[0.018]^{*}$} & [0.019] & [0.019] & [0.019] \\
\hline \multirow[t]{2}{*}{ Hispanic } & -0.013 & -0.046 & -0.015 & -0.02 & -0.011 & -0.012 \\
\hline & [0.028] & {$[0.016]^{\star \star}$} & [0.017] & {$[0.017]$} & {$[0.017]$} & {$[0.017]$} \\
\hline \multirow[t]{2}{*}{ Asian } & -0.026 & -0.068 & -0.063 & -0.072 & -0.056 & -0.048 \\
\hline & [0.035] & {$[0.020]^{\star *}$} & {$[0.020]^{\star *}$} & {$[0.020]^{\star *}$} & {$[0.020]^{\star *}$} & {$[0.020]^{*}$} \\
\hline \multirow[t]{2}{*}{ Other } & -0.013 & -0.039 & -0.024 & -0.026 & -0.023 & -0.016 \\
\hline & [0.039] & [0.025] & [0.025] & {$[0.025]$} & {$[0.025]$} & [0.024] \\
\hline \multirow[t]{2}{*}{ Age } & & 488.089 & 483.958 & 498.736 & 505.248 & 504.52 \\
\hline & & {$[110.641]^{\star *}$} & {$[110.111]^{\star \star}$} & {$[109.414]^{\star *}$} & {$[108.913]^{\star *}$} & {$[107.444]^{\star *}$} \\
\hline \multirow[t]{2}{*}{$\mathrm{Age}^{\wedge} 2$} & & -96.648 & -95.941 & -98.855 & -100.032 & -100.028 \\
\hline & & {$[21.419]^{\star \star}$} & {$[21.318]^{\star *}$} & {$[21.180]^{\star *}$} & {$[21.086]^{\star *}$} & {$[20.798]^{\star *}$} \\
\hline \multirow[t]{2}{*}{$\mathrm{Age}^{\wedge} 3$} & & 9.525 & 9.465 & 9.751 & 9.856 & 9.867 \\
\hline & & {$[2.062]^{\star \star}$} & {$[2.053]^{\star \star}$} & {$[2.039]^{\star \star}$} & {$[2.031]^{\star \star}$} & {$[2.002]^{\star \star}$} \\
\hline \multirow[t]{2}{*}{$\mathrm{Age}^{\wedge} 4$} & & -0.467 & -0.464 & -0.478 & -0.483 & -0.484 \\
\hline & & {$[0.099]^{\star *}$} & {$[0.098]^{\star *}$} & {$[0.098]^{\star *}$} & {$[0.097]^{\star *}$} & {$[0.096]^{\star *}$} \\
\hline \multirow[t]{2}{*}{$\mathrm{Age}^{\wedge} 5$} & & 0.009 & 0.009 & 0.009 & 0.009 & 0.009 \\
\hline & & {$[0.002]^{\star *}$} & {$[0.002]^{\star *}$} & {$[0.002]^{\star *}$} & {$[0.002]^{\star *}$} & {$[0.002]^{\star *}$} \\
\hline \multirow[t]{2}{*}{ female } & & 0.061 & 0.061 & 0.063 & 0.061 & 0.069 \\
\hline & & {$[0.011]^{\star \star}$} & {$[0.011]^{\star \star}$} & {$[0.011]^{\star *}$} & {$[0.011]^{\star *}$} & {$[0.011]^{\star \star}$} \\
\hline \multicolumn{7}{|c|}{ Socioeconomic Status Quintiles: } \\
\hline \multirow[t]{2}{*}{2} & & & 0.024 & 0.021 & 0.018 & 0.021 \\
\hline & & & [0.018] & {$[0.018]$} & {$[0.018]$} & {$[0.018]$} \\
\hline \multirow[t]{2}{*}{3} & & & 0.076 & 0.067 & 0.055 & 0.052 \\
\hline & & & {$[0.018]^{\star *}$} & {$[0.019]^{\star *}$} & {$[0.019]^{\star *}$} & {$[0.019]^{\star *}$} \\
\hline \multirow[t]{2}{*}{4} & & & 0.081 & 0.073 & 0.054 & 0.047 \\
\hline & & & {$[0.019]^{\star *}$} & {$[0.021]^{\star *}$} & {$[0.021]^{\star *}$} & {$[0.021]^{*}$} \\
\hline \multirow{2}{*}{\multicolumn{2}{|c|}{5 (highest) }} & & 0.079 & 0.074 & 0.048 & 0.042 \\
\hline & & & {$[0.020]^{\star *}$} & {$[0.022]^{\star *}$} & {$[0.023]^{\star}$} & [0.022] \\
\hline \multicolumn{7}{|c|}{ Number of Siblings: } \\
\hline \multirow[t]{2}{*}{1} & & & & -0.066 & -0.064 & -0.063 \\
\hline & & & & {$[0.013]^{\star *}$} & {$[0.013]^{\star *}$} & {$[0.013]^{\star *}$} \\
\hline \multirow[t]{2}{*}{2} & & & & -0.079 & -0.079 & -0.07 \\
\hline & & & & {$[0.017]^{\star *}$} & {$[0.016]^{\star *}$} & {$[0.017]^{\star *}$} \\
\hline \multirow[t]{2}{*}{3} & & & & -0.135 & -0.134 & -0.117 \\
\hline & & & & {$[0.025]^{\star *}$} & {$[0.025]^{\star *}$} & {$[0.025]^{\star \star}$} \\
\hline \multirow[t]{2}{*}{4} & & & & -0.14 & -0.13 & -0.114 \\
\hline & & & & {$[0.044]^{\star *}$} & {$[0.044]^{\star *}$} & {$[0.044]^{\star *}$} \\
\hline 5 & & & & -0.102 & -0.081 & -0.042 \\
\hline & & & & {$[0.059]$} & {$[0.059]$} & {$[0.057]$} \\
\hline 6 & & & & -0.122 & -0.126 & -0.136 \\
\hline & & & & {$[0.077]$} & [0.075] & [0.073] \\
\hline Family c & ion: & & & & & \\
\hline Single & al parent & & & -0.019 & -0.017 & -0.013 \\
\hline & & & & {$[0.017]$} & {$[0.017]$} & {$[0.017]$} \\
\hline Biolog & nt and oth & arent & & -0.039 & -0.051 & -0.039 \\
\hline & & & & [0.053] & {$[0.053]$} & {$[0.052]$} \\
\hline
\end{tabular}




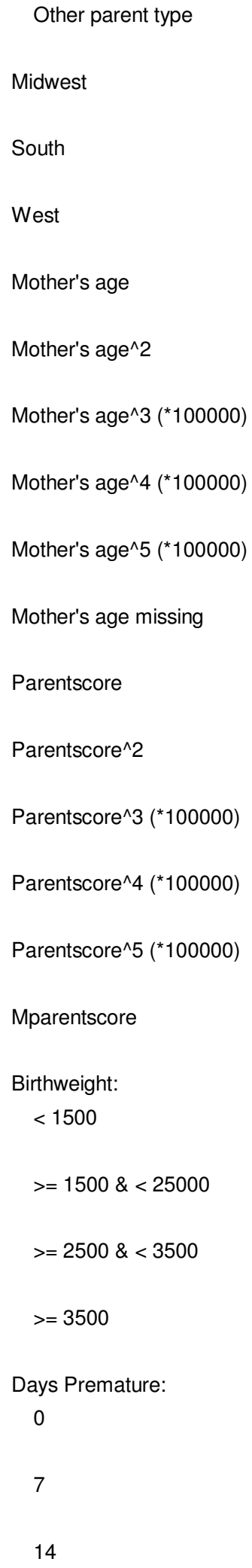

\begin{tabular}{|c|c|c|}
\hline-0.044 & -0.051 & 0.002 \\
\hline [0.110] & [0.108] & [0.111] \\
\hline-0.038 & -0.035 & -0.031 \\
\hline [0.048] & [0.047] & [0.047] \\
\hline 0.043 & 0.058 & 0.06 \\
\hline [0.056] & [0.056] & [0.055] \\
\hline 0.016 & 0.02 & 0.011 \\
\hline [0.063] & [0.063] & [0.063] \\
\hline-0.14 & -0.118 & -0.07 \\
\hline [0.669] & [0.666] & [0.660] \\
\hline 0.012 & 0.01 & 0.005 \\
\hline [0.047] & [0.047] & [0.046] \\
\hline-43.527 & -35.908 & -13.402 \\
\hline [160.510] & [159.846] & [158.698] \\
\hline 0.744 & 0.598 & 0.146 \\
\hline [2.674] & [2.665] & [2.648] \\
\hline-0.005 & -0.004 & 0 \\
\hline$[0.017]$ & {$[0.017]$} & [0.017] \\
\hline-0.506 & -0.41 & -0.22 \\
\hline \multirow[t]{27}{*}{ [3.718] } & [3.697] & [3.664] \\
\hline & -0.269 & -0.3 \\
\hline & [1.226] & [1.220] \\
\hline & 0.015 & 0.017 \\
\hline & [0.080] & {$[0.080]$} \\
\hline & -38.583 & -48.659 \\
\hline & [256.303] & [256.023] \\
\hline & 0.485 & 0.669 \\
\hline & [4.012] & [4.014] \\
\hline & -0.002 & -0.004 \\
\hline & [0.025] & [0.025] \\
\hline & -1.741 & -1.897 \\
\hline & [7.321] & [7.253] \\
\hline & & -0.355 \\
\hline & & {$[0.090]^{* *}$} \\
\hline & & -0.051 \\
\hline & & {$[0.087]$} \\
\hline & & 0.068 \\
\hline & & [0.086] \\
\hline & & 0.132 \\
\hline & & [0.086] \\
\hline & & 0.103 \\
\hline & & {$[0.060]$} \\
\hline & & 0.032 \\
\hline & & {$[0.066]$} \\
\hline & & -0.022 \\
\hline & & [0.069] \\
\hline
\end{tabular}




\begin{tabular}{|c|c|c|c|c|c|c|}
\hline \multirow[t]{2}{*}{21} & & & & & & 0.075 \\
\hline & & & & & & {$[0.070]$} \\
\hline \multirow[t]{2}{*}{28} & & & & & & -0.097 \\
\hline & & & & & & {$[0.078]$} \\
\hline \multirow[t]{2}{*}{35} & & & & & & 0.005 \\
\hline & & & & & & {$[0.076]$} \\
\hline \multirow[t]{2}{*}{42} & & & & & & 0.005 \\
\hline & & & & & & {$[0.087]$} \\
\hline \multirow[t]{2}{*}{49} & & & & & & -0.061 \\
\hline & & & & & & {$[0.076]$} \\
\hline \multirow[t]{2}{*}{56} & & & & & & 0.045 \\
\hline & & & & & & [0.085] \\
\hline \multirow[t]{2}{*}{63} & & & & & & -0.059 \\
\hline & & & & & & [0.075] \\
\hline \multirow[t]{2}{*}{70} & & & & & & -0.291 \\
\hline & & & & & & {$[0.083]^{* *}$} \\
\hline \multirow[t]{2}{*}{77} & & & & & & -0.365 \\
\hline & & & & & & {$[0.074]^{\star *}$} \\
\hline \multirow{2}{*}{\multicolumn{2}{|c|}{ Singleton birth }} & & & & & -0.001 \\
\hline & & & & & & {$[0.060]$} \\
\hline \multirow{2}{*}{\multicolumn{2}{|c|}{ Twin birth }} & & & & & -0.077 \\
\hline & & & & & & {$[0.060]$} \\
\hline \multirow{2}{*}{\multicolumn{2}{|c|}{ Triplet or more birth }} & & & & & - \\
\hline & & & & & & - \\
\hline \multirow[t]{2}{*}{ Constant } & 0.013 & -982.802 & -973.364 & $-1,002.51$ & $-1,015.15$ & $-1,012.18$ \\
\hline & {$[0.014]$} & {$[227.402]^{\star *}$} & {$[226.276]^{\star \star}$} & {$[224.953]^{\star *}$} & {$[224.352]^{\star *}$} & {$[221.337]^{* *}$} \\
\hline Observations & 10132 & 10132 & 10132 & 10132 & 10132 & 10132 \\
\hline R-squared & 0.14 & 0.68 & 0.68 & 0.68 & 0.68 & 0.71 \\
\hline
\end{tabular}

NOTES: See notes to Table 2. The columns in this table report the full regression results of specifications (1) through (6) in Table 2. 